\title{
The evolution of head structures in lower Diptera
}

\author{
Katharina Schneeberg*, and Rolf G Beutel \\ Institut für Spezielle Zoologie und Evolutionsbiologie, FSU Jena, 07743 Jena, Germany \\ *Corresponding author's e-mail address: Katharina.Schneeberg@gmx.de
}

Published online: 1 December 2014 (version 1)

Cite as: Schneeberg K. and Beutel R.G, ScienceOpen Research 2014 (DOI: 10.14293/S2199-1006.1.SOR-LIFE.ALTCE1.v1)

Reviewing status: Please note that this article is under continuous review. For the current reviewing status and the latest referee's comments please click here or scan the QR code at the end of this article.

Primary discipline: Life sciences

Keywords: Diptera, Morphology, Head, Evolution

\begin{abstract}
The head of adult dipterans is mainly characterized by modifications and more or less far-reaching reductions of the mouthparts (e.g., mandibles and maxillae), linked with the specialization on liquid food and the reduced necessity to process substrates mechanically. In contrast, the compound eyes and the antennae, sense organs used for orientation and for finding a suitable mating partner and oviposition site, are well developed. Some evolutionary novelties are specific adaptations to feeding on liquefied substrates, such as labellae with furrows or pseudotracheae on their surface, and the strongly developed pre- and postcerebral pumping apparatuses. In some dipteran groups specialized on blood, the mandibles are still present as piercing stylets. They are completely reduced in the vast majority of families. Within the group far-reaching modifications of the antennae take place, with a strongly reduced number of segments and a specific configuration in Brachycera. The feeding habits and mouthparts of dipteran larvae are much more diverse than in the adults. The larval head is prognathous and fully exposed in the dipteran groundplan and most groups of lower Diptera. In Tipuloidea and Brachycera it is partly or largely retracted, and the sclerotized elements of the external head capsule are partly or fully reduced. The larval head of Cyclorrhapha is largely reduced. A complex and unique feature of this group is the cephaloskeleton. The movability of the larvae is limited due to the lack of thoracic legs. This can be partly compensated by the mouthparts, which are involved in locomotion in different groups. The mouth hooks associated with the cyclorrhaphan cephaloskeleton provide anchorage in the substrate.
\end{abstract}

\section{INTRODUCTION}

With approximately 170,000 described species, Diptera (true flies) are one of the extremely species-rich groups of Holometabola [1]. Fossil dipterans are known since the Triassic [2]. Recent species occur worldwide, on all continents including Antarctica and in all zoogeographic regions [3]. The number of individuals is often extremely high. Many species (e.g., Anopheles spp. and Simulium spp., tsetse) are important as vectors of diseases (e.g., malaria, river blindness, and sleeping sickness) or acricultural pests (e.g., Hessian fly), but dipteran maggots can play a positive role by processing excrements and cadavers [e.g. 4], and in forensic entomology and microsurgery.

Diptera are very versatile in their ecology [5]. The adults are relatively uniform in their morphology, whereas the immature stages are highly variable in their structural features, life habits, and habitats. The monophyly of Diptera has never been seriously challenged [see 6] but due to a surprising scarcity of morphological data a well-founded groundplan of the order is not established yet. This impedes interordinal comparisons and the understanding of the early evolution within the group.

Traditionally, Diptera is subdivided into "Nematocera" and Brachycera [7]. The former is a paraphyletic assemblage (lower Diptera) containing all non-brachyceran families, usually characterized by a slender habitus as adults and a welldeveloped larval head [8]. The lower Diptera, which are the main focus of this study, comprise 37 extant families which were recently assigned to eight subgroups: Deuterophlebiomorpha, Nymphomyiomorpha, Tipulomorpha, Ptychopteromorpha, Psychodomorpha, Culicomorpha, Perissommatomorpha, and Bibionomorpha [1]. The composition and phylogenetic relationships of these groups are still discussed controversially. In older contributions Tipulomorpha were placed as the sistergroup of the remaining Diptera [8-13], supported by characters of the wing venation of fossil and extant species [14] and by features of the pretarsus [12] and wing stalk [15]. This concept is not supported in most recent contributions [16-21]. In some studies, Tipulomorpha form the sister group of Brachycera [16-19, $22]$, whereas they were placed as sister to the remaining Diptera excluding Deuterophlebiidae and Nymphomyiidae in a comprehensive study of Wiegmann et al. [23]. Oosterbroek \& Courtney [16], Yeates \& Wiegmann $[17,18]$ and Yeates et al. [19] suggested a clade Ptychopteromorpha + Culicomorpha as the most basal branch of Diptera. A basal placement of 
Deuterophlebiidae $[20,23]$ or Nymphomyiidae $([21,24]$ [Deuterophlebiidae is not included in the taxon sampling in the study of Lambkin et al.]) is mainly suggested by analyses of molecular data. Alternatively, Nymphomyiidae were grouped with Axymyiidae, both forming the sistergroup of Culicomorpha [20]. Different groups were considered as sistergroup of the monophyletic Brachycera, a subgroup of Psychodomorpha [9, $10]$, implying the paraphyly of this lineage, Anisopodidae [14, $16,25]$, or a clade Anisopodidae + Culicomorpha + Bibionomorpha based on characters of the wing stalk [15] Hennig [8] and Häckman \& Vaisänen [24] suggested a close relationship between Bibionomorpha and Brachycera, and this is also supported by analyses of molecular data [20, $23,26]$.

The reconstruction of the phylogeny and character evolution in Diptera was strongly impeded by the lack of well-documented morphological data. A series of studies on larval and adults head structures were published in the framework of a recent project on dipteran morphology and evolution [e.g., 27-33], mainly based on innovative techniques optimized by the Entomology Group in the Phyletisches Museum (Institut für Spezielle Zoologie und Evolutionsbiologie, FSU Jena) in the last years [e.g., 34]. An extensive data set was compiled for adults and immature stages. The main aim of the present study is a formal evaluation of the character evolution and the reconstruction of the ordinal groundplan. The recent comprehensive phylogenetic study of Wiegmann et al. [23] is an ideal basis, as the taxon sampling of the present study was largely coordinated with the FLYTREE project [see 23]. Only few taxa were not available for anatomical investigations. Morphological characters were mapped on the phylogenetic tree based on the most comprehensive data set analyzed so far [23]. Based on this evaluation, an evolutionary scenario was developed, with emphasis on the adult head and feeding apparatus and on larval cepahlic features and life habits.

\section{MATERIALS AND METHODS Taxa examined}

Adults of 43 species and larvae of 31 were examined. The taxon sampling includes at least one representative of each of the lower dipteran families (with few exceptions) and was coordinated with the FLYTREE project (see taxon sampling in [23]). External and internal head structures of adults of 28 species and larvae of 10 species were examined in detail. The list of species used in the studies is given in Tables 1 and 2 .

\section{Methods}

Scanning electron microscopy (SEM). Scanning electron microscopy was used to visualize external features. Specimens were dehydrated in an ascending ethanol series (70\%-100\% ethanol and $99.9 \%$ acetone) and dried at the critical point (EmiTech K850 Critical point Dryer, Quorum Technologies Ltd., Ashford, Kent, UK). They were glued on a fine pin, sputter coated with gold (EmiTech K500 sputter coater, Quorum Technologies Ltd., Ashford, Kent, UK), and mounted on a rotatable specimen holder [35]. Images were taken with a Philips XL 30 ESEM (Philips, Amsterdam, The Netherlands) using Scandium software (Olympus, Münster, Germany). The figure plates were processed with Adobe Photoshop ${ }^{\circledR}$ (Adobe, San José, USA) and Adobe Illustrator ${ }^{\circledR}$ (Adobe, San José, USA). Confocal Laser Scanning Microscopy (CLSM). For the investigation of the skeletal elements and for an overview of the arrangement of muscles, images were taken with a CLSM. The specimens were mounted between two cover glasses with a drop of glycerin. Images were taken with an argon laser (488 $\mathrm{nm}$ ) on a LSM 510 (Carl Zeiss AG, Göttingen, Germany). As insect cuticle, musculature, and nerves are autofluorescent, a treatment with antibodies is not necessary [36].

Histology. Histological sections were used to investigate the internal structures. Specimens were fixed in formaldehydeethanol-acetic acid (FAE, 3:6:1) and dehydrated with ethanol (80\%-100\% ethanol) and acetone (99.9\%). They were embedded in Aradite (CY 212, Agar Scientific, Stansted/Essex, UK), sectioned $(1 \mu \mathrm{m} / 1.5 \mu \mathrm{m})$ with a diamond-knife (Elementsix) on a microtome (HM 360, Microm, Walldorf, Germany), and stained with Toluidine blue and Pyronin G (Waldeck GmbH and Co. KG/Division Chroma, Münster, Germany). The sections were digitalized with a Zeiss Axioscope (Carl Zeiss AG, Jena, Germany) with a PixeLINK PL-A622C and PixeLINK PL-B686 (PixeLINK, Ottawa, Canada) digital camera, using the software PixeLINK Capture OEM 7.12 (PixeLINK, Ottawa, Canada). The alignment of the image stack was calculated by AutoAligner ${ }^{\circledR} 6$ (Bitplane AG, Zürich, Suisse) and Amira ${ }^{\circledR} 5.3$ (Visage Imaging GmbH, Berlin, Germany) software.

Micro Computer Tomography (MicroCT). Micro Computer Tomography (MicroCT) was used to document external and internal structures. Specimens were dehydrated with an ascending ethanol series (70-100\% ethanol) and acetone (99.9\%), dried at the critical point (EmiTech K850 Critical point Dryer, Quorum Technologies Ltd., Ashford, Kent, UK) and mounted on a metal rod with super glue or specific dough. The scans were performed at Beamline BW2 of the DESY (Deutsches Elektronen-Synchrotron, Hamburg; see [37]) using a stable low photon energy beam (8kV) and absorptions contrast (see [38, 39]). Further scans were performed on a Skyscan 1172 microCT scanner (Bruker, Billerica, Massachusetts, USA).

Computer-based three-dimensional (3D) reconstruction. The arrangement of external and internal structures was visualized using computer-based 3D reconstructions, based on digitalized and aligned section series. Image stacks of head structures were reconstructed using Imaris ${ }^{\circledR}$ 6.2.0 (Bitplane AG, Zürich, Suisse) and Amira ${ }^{\circledR} 5.3$ (Visage Imaging GmbH, Berlin, Germany) software. The surfaces were polished, smoothed, and rendered with Maya ${ }^{\circledR} 2012$ (Autodesk, San Rafael, USA). 
Table 1. List of adult Taxa examined.

\begin{tabular}{|c|c|c|c|}
\hline Taxon & & Fixation & Origin of material \\
\hline \multicolumn{4}{|l|}{ Diptera } \\
\hline Anisopodidae & Sylvicola fenestralis (Scopoli, 1763) & $70 \% \mathrm{EtOH}$ & Germany, Thuringia, Jena \\
\hline Asilidae & Silpnogaster aemula (Meigen, 1920) & $70 \% \mathrm{EtOH}$ & Germany, Thuringia, vicinity of Jena \\
\hline Axymyiidae & Axymyia furcata McAtee, 1921 & $95 \% \mathrm{EtOH}$ & $\begin{array}{l}\text { USA, North Carolina, Haywood County, Great Smoky Mountains } \\
\text { National Park }\end{array}$ \\
\hline Bibionidae & Bibio marci Linnaeus, 1758 & $70 \% \mathrm{EtOH}$ & Germany, Thuringia, Jena \\
\hline Blephariceridae & Edwardsina gracilis Edwards, 1929 & $70 \% \mathrm{EtOH}$ & Chile, Las Lagos, Parque National Puyehue, Rio Anticure \\
\hline \multirow[t]{2}{*}{ Bombyliidae } & Bombylius major Linnaeus, 1758 & \multicolumn{2}{|c|}{ Data taken from Szucsich \& Krenn [60] } \\
\hline & Hemipenthes mario (Linnaeus, 1758) & \multicolumn{2}{|c|}{ Data taken from Szucsich \& Krenn [60] } \\
\hline Cecidomyiidae & Mayetiola destructor (Say, 1817) & $70 \% \mathrm{EtOH}$ & $\begin{array}{l}\text { USA, North Dakota, in culture (Entomology Department, North } \\
\text { Dakota State University) }\end{array}$ \\
\hline Ceratopogonidae & Culicoides impunctatus (Goetghebuer, 1920) & \multicolumn{2}{|c|}{ Data taken from Gad [113] } \\
\hline Chaoboridae & Chaoborus christallinus (De Geer, 1776) & $70 \% \mathrm{EtOH}$ & $\begin{array}{l}\text { Germany, Thuringia, Jena, in culture (Institut für Spezielle Zoologie } \\
\text { und Evolutionsbiologie) }\end{array}$ \\
\hline Corethrellidae & Corethrella appendiculata Grabham, 1906 & $70 \% \mathrm{EtOH}$ & $\begin{array}{l}\text { USA, Florida, Vero Beach, in culture (Florida Medical Entomology } \\
\text { Laboratory) }\end{array}$ \\
\hline \multirow[t]{4}{*}{ Culicidae } & Aedes aegypti (Linnaeus, 1962) & \multicolumn{2}{|c|}{ Data taken from Christophers [99] } \\
\hline & Anopheles maculipennis Meigen, 1818 & $70 \% \mathrm{EtOH}$ & Germany, Nordrhein-Westfalen, Höxter \\
\hline & Culex pipiens Linnaeus, 1758 & $70 \% \mathrm{EtOH}$ & Germany, Thuringia, Orlamünde, near Riverside \\
\hline & Culiseta annulata (Schrank, 1776) & \multicolumn{2}{|c|}{ Data taken from Schiemenz [59] } \\
\hline Cylindrotomidae & Cylindrotoma distictissima (Meigen, 1818) & $70 \% \mathrm{EtOH}$ & Italy, Piemonte, Cuneo Marora, San Sebastiano \\
\hline Deuterophlebiidae & Deuterophlebia coloradensis Pennak, 1945 & $95 \% \mathrm{EtOH}$ & USA, Colorado, Boulder County, Boulder Creek \\
\hline Drosophilidae & Drosophila melanogaster Meigen, 1830 & FAE & $\begin{array}{l}\text { Germany, Thuringia, Jena, in culture (wildtype Canton S) (Max- } \\
\text { Planck-Institute for Chemical Ecology) }\end{array}$ \\
\hline Glossinidae & $\begin{array}{l}\text { Glossina palpalis gambiensis } \\
\text { Vanderplank, } 1911\end{array}$ & FAE & Austria, Wien, in culture (International Atomic Energy Agency) \\
\hline Limoniidae & Limonia sp. Meigen, 1803 & $70 \% \mathrm{EtOH}$ & Germany, Thuringia, vicinity of Jena \\
\hline Keroplatidae & Macrocera phalerata Meigen, 1818 & $70 \% \mathrm{EtOH}$ & Germany, Thuringia, vicinity of Jena \\
\hline Mycetophilidae & Exechia separata Lundström, 1912 & $70 \% \mathrm{EtOH}$ & Germany, Thuringia, vicinity of Jena \\
\hline Nymphomyiidae & Nymphomyia dolichopeza Courtney, 1994 & $95 \% \mathrm{EtOH}$ & USA, North Carolina, Macon County, Coweeta Hydrologica Lab \\
\hline Pediciidae & Pedicia rivosa (Linnaeus, 1758) & $70 \% \mathrm{EtOH}$ & Italy, Piemonte, Torina, Villar Péllice \\
\hline Psychodidae & Psychoda alternata Say, 1824 & $70 \% \mathrm{EtOH}$ & Germany, Hamburg, Eimsbüttel \\
\hline Ptychopteridae & Ptychoptera contaminata (Linnaeus, 1758) & $70 \% \mathrm{EtOH}$ & Germany, Thuringia, Jena \\
\hline Scatopsidae & Coboldia fuscipes (Meigen, 1930) & $95 \% \mathrm{EtOH}$ & USA, specific location unknown \\
\hline Sciaridae & Spathobdella falcifera (Lengersdorf, 1933) & $70 \% \mathrm{EtOH}$ & Germany, Thuringia, Jena \\
\hline Simuliidae & Wilhelmia equina (Linnaeus, 1746) & \multicolumn{2}{|c|}{ Data taken from Wenk [95] } \\
\hline Stratiomyiidae & Pachygaster atra (Panzer, 1798) & $70 \% \mathrm{EtOH}$ & Germany, Thuringia, Schinditz \\
\hline Syrphidae & Eristalis arbustorum (Linnaeus, 1758) & \multicolumn{2}{|c|}{ Data taken from Schiemenz [59] } \\
\hline Tabanidae & Tabanus sulcifrons Macquart, 1855 & \multicolumn{2}{|c|}{ Data taken from Bonhag [98] } \\
\hline \multirow[t]{2}{*}{ Tanyderidae } & Mischoderus sp. Handlirsch, 1909 & $70 \% \mathrm{EtOH}$ & New Zealand, Mount Arthur, Flora Hut, 920m \\
\hline & Protoplasa fitchii Osten Sacken, 1860 & \multicolumn{2}{|c|}{ Data taken from Williams [94] } \\
\hline Thaumaleidae & Androprosopa sp. Mik, 1898 & $95 \% \mathrm{EtOH}$ & USA, Oregon, Marion County, Squirrel Creek 1035m \\
\hline Tipulidae & Tipula paludosa Meigen, 1830 & $70 \% \mathrm{EtOH}$ & Germany, Thuringia, Jena \\
\hline Trichoceridae & Trichocera saltator (Harris, 1776) & $\mathrm{FAE}$ & Germany, Thuringia, Jena \\
\hline \multicolumn{4}{|l|}{ Mecoptera } \\
\hline Boreidae & Caurinus dectes Russel, 1979 & \multicolumn{2}{|c|}{ Data taken from Beutel et al. [81] } \\
\hline Meropidae & Merope tuber Newman, 1838 & \multicolumn{2}{|c|}{ Data taken from Friedrich et al. [82] } \\
\hline Nannochoristidae & Nannochorista neotropica Navás, 1928 & \multicolumn{2}{|c|}{ Data taken from Beutel \& Baum [80] } \\
\hline $\begin{array}{l}\text { Panorpidae } \\
\text { Lepidoptera }\end{array}$ & Panorpa communis Linnaeus, 1758 & \multicolumn{2}{|c|}{ Data taken from Heddergott [115] } \\
\hline Micropterigidae & Micropterix calthella (Linnaeus, 1761) & \multicolumn{2}{|c|}{ Data taken from Hannemann [171] } \\
\hline Siphonaptera & Ctenocenhalus canis (Curtis 1826) & \multicolumn{2}{|c|}{ Data taken from Wenk [83] } \\
\hline
\end{tabular}

Abbreviation: EtOH - ethanol, FAE - formaldehyde-ethanol-acetic acid (3:6:1).

Cladistic analyses. The data matrix comprises 76 characters of adults of 42 terminal taxa (species) and 70 larval characters for 30 species. For character coding, tree calculation, and cladistic character analysis WinClada [186] software was used (Rachet Island Hopper, 1000 replicates). All characters were treated as nonadditive and equally weighted. In the 
Table 2. List of larval taxa examined.

\begin{tabular}{|c|c|c|c|}
\hline Taxon & & Fixation & Origin of material \\
\hline \multicolumn{4}{|l|}{ Diptera } \\
\hline \multicolumn{2}{|l|}{ Anisopodidae } & \multicolumn{2}{|c|}{ Data taken from Anthon $[45,164]$} \\
\hline Axymyiidae & Axymyia furcata McAtee, 1921 & $95 \% \mathrm{EtOH}$ & USA, North Carolina, Macon County \\
\hline \multirow{2}{*}{ Bibionidae } & Bibio marci Linnaeus, 1758 & $70 \% \mathrm{EtOH}$ & Germany, Thuringia, Jena \\
\hline & Bibio sp. Geoffroy, 1962 & \multicolumn{2}{|c|}{ Data taken from Cook [46] } \\
\hline \multicolumn{2}{|l|}{ Blephariceridae } & \multicolumn{2}{|c|}{ Data taken from Anthon \& Lyneborg [63] } \\
\hline Ceratopogonidae & Dasyhelea sp. Kieffer, 1911 & \multicolumn{2}{|c|}{ Data taken from Lieven [135] } \\
\hline Chironomidae & Chironomus sp. Meigen, 1803 & \multicolumn{2}{|c|}{ Data taken from Cook [74]; Gouin [155] } \\
\hline Corethrellidae & Corethrella appendiculata & $70 \% \mathrm{EtOH}$ & $\begin{array}{l}\text { USA, Florida, in culture (Florida Medical Entomology } \\
\text { Laboratory; University of Florida) }\end{array}$ \\
\hline \multirow[t]{4}{*}{ Culicidae } & Culex sp. Linnaeus, 1758 & $70 \% \mathrm{EtOH}$ & Germany, Thuringia, Jena \\
\hline & Culiseta sp. Felt 1904 & \multicolumn{2}{|c|}{ Data taken from Cook [73] } \\
\hline & Anopheles sp. Meigen, 1818 & $70 \% \mathrm{EtOH}$ & Germany, Thuringia, Jena \\
\hline & Anopheles sp. Meigen, 1818 & \multicolumn{2}{|c|}{ Data taken from Cook [73]; Schremmer [154] } \\
\hline Deuterophlebiidae & Deuterophlebia sp. Edwards 1922 & \multicolumn{2}{|c|}{ Data taken from Courtney [172] } \\
\hline Dixidae & Dixa sp. Meigen, 1816 & \multicolumn{2}{|c|}{ Data taken from Felix [66]; Schremmer [173] } \\
\hline Limoniidae & Limonia sp. Meigen, 1803 & \multicolumn{2}{|c|}{ Data taken from Lindner [22]; Oosterbroek \& Theowald [62] } \\
\hline Mycetophilidae & Exechia separata Lundström, 1912 & $70 \% \mathrm{EtOH}$ & Germany, Thuringia, Jena \\
\hline Nymphomyiidae & Nymphomyia dolichopeza Courtney, 1994 & $95 \% \mathrm{EtOH}$ & USA, North Carolina, Macon County \\
\hline Pediciidae & Dicranota sp. Zetterstedt, 1838 & \multicolumn{2}{|c|}{ Data taken from Cook [46] } \\
\hline Psychodidae & & \multicolumn{2}{|c|}{ Data taken from Anthon [45] } \\
\hline Ptychopteridae & Bittacomorpha sp. Westwood, 1835 & \multicolumn{2}{|c|}{ Data taken from Kramer [72] } \\
\hline Sciaridae & Phaenobremia aphidimyza (Rondani, 1847) & \multicolumn{2}{|c|}{ Data taken from Solinas [47] } \\
\hline Simuliidae & Simulium sp. Latreille, 1802 & \multicolumn{2}{|c|}{ Data taken from Cook [46] } \\
\hline Stratiomyiidae & Odontomyia sp. Meigen, 1803 & \multicolumn{2}{|c|}{ Data taken from Cook [46] } \\
\hline Tabanidae & Tabanus sp. Linnaeus, 1758 & \multicolumn{2}{|c|}{ Data taken from Cook [46] } \\
\hline Tanyderidae & Protanyderus sp. Handlirsch, 1909 & \multicolumn{2}{|c|}{ Data taken from Wipfler et al. [32] } \\
\hline Thaumaleidae & Androprosopa sp. Mik, 1898 & $95 \% \mathrm{EtOH}$ & USA, Oregon, Benton County \\
\hline Therevidae & & \multicolumn{2}{|c|}{ Data taken from Cook [46] } \\
\hline \multirow[t]{2}{*}{ Tipulidae } & Tipula irrorata Marquart, 1926 & $70 \% \mathrm{EtOH}$ & Germany, Thuringia, Jena \\
\hline & Tipula montium Egger, 1863 & $70 \% \mathrm{EtOH}$ & Germany, Thuringia, Jena \\
\hline Trichoceridae & Trichocera sp. Meigen, 1803 & \multicolumn{2}{|c|}{ Data taken from Karandikar [174]; Anthon [45]; Brindle [175] } \\
\hline \multicolumn{4}{|l|}{ Mecoptera } \\
\hline Nannochoristidae & Nannochorista sp. Tillyard, 1917 & \multicolumn{2}{|c|}{ Data taken from Beutel et al. [136] } \\
\hline Panorpidae & Panorpa communis Linnaeus, 1758 & \multicolumn{2}{|c|}{ Data taken from Bierbrodt [141] } \\
\hline Siphonaptera & & & \\
\hline Ceratophylidae & Nosopsyllus fasciatus (Bosc, 1800) & Data taken & Sharif [139] \\
\hline
\end{tabular}

Abbreviation: EtOH - ethanol, FAE - formaldehyde-ethanol-acetic acid (3:6:1).

analyses of the combined data set (adult and larval head structures) chimera (different genera of the same monophyletic family) were used in some cases (Ptychopteridae, Simuliidae, Ceratopogonidae, Blephariceridae, Anisopodidae, Psychodidae, and Pediciidae). For tracing the character evolution, cephalic features of adults and of larvae were mapped onto the cladogram of Wiegmann et al. [23], using the function implemented in Mesquite (trace characters over trees, reconstruction method parsimony ancestral states; [40]).

\section{RESULTS}

\section{Phylogenetic results}

The list of phylogenetic relevant characters is given in Appendix 1. For the character state matrices see Appendix 2 (adult head structures) and Appendix 3 (larval head structures). The Ratchet Island Hopper analyses resulted in three trees. The strict consensus tree is given in Figure 1A. Diptera and Brachycera are monophyletic. The resolution in the strict consensus tree is low concerning the phylogenetic relationships of the lower dipteran families. None of the currently recognized eight subgroups [1] was confirmed as monophyletic in the analysis. The superfamily Tipuloidea (Tipulomorpha excluding Trichoceridae) is monophyletic, and clades, comprising Culicidae and Simuliidae, and Nymphomyiidae and Deuterophlebiidae, respectively, were supported. Axymyiidae were placed as sister to the remaining groups of Diptera.

The analyses of characters of the adult head resulted in 144 trees. Diptera (and also Brachycera) is paraphyletic in the strict consensus tree (Figure 1C), as Nannochorista is nested within dipteran groups. Like in the analyses of the complete data set, Nymphomyiidae and Deuterophlebiidae are closest relatives. Larval character analyses resulted in 90 trees. The strict consensus tree is shown in Figure 1B. Diptera, Brachycera, and Tipuloidea (excl. Trichoceridae) are monophyletic. Deuterophlebiidae is placed with Simuliidae and 
A

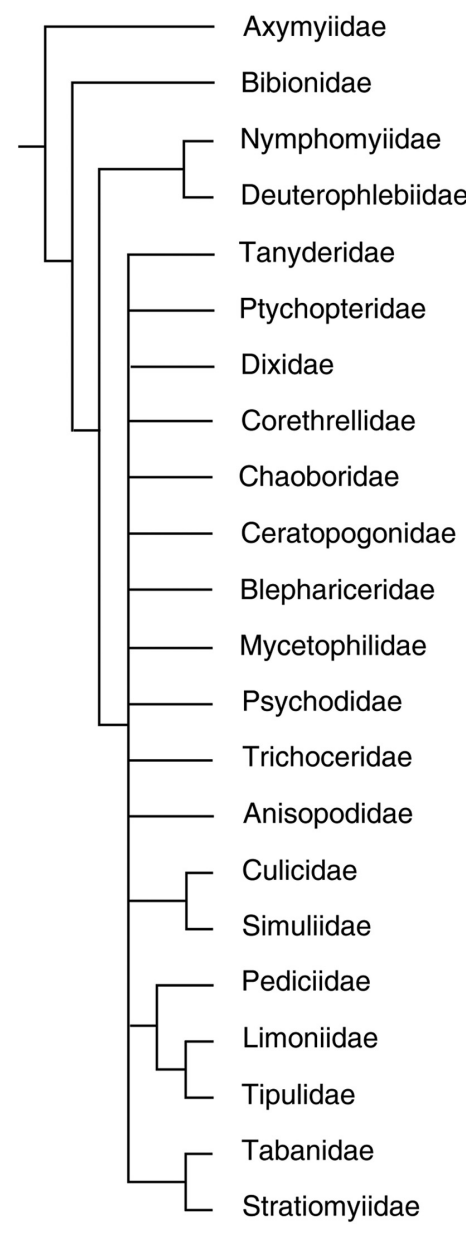

B

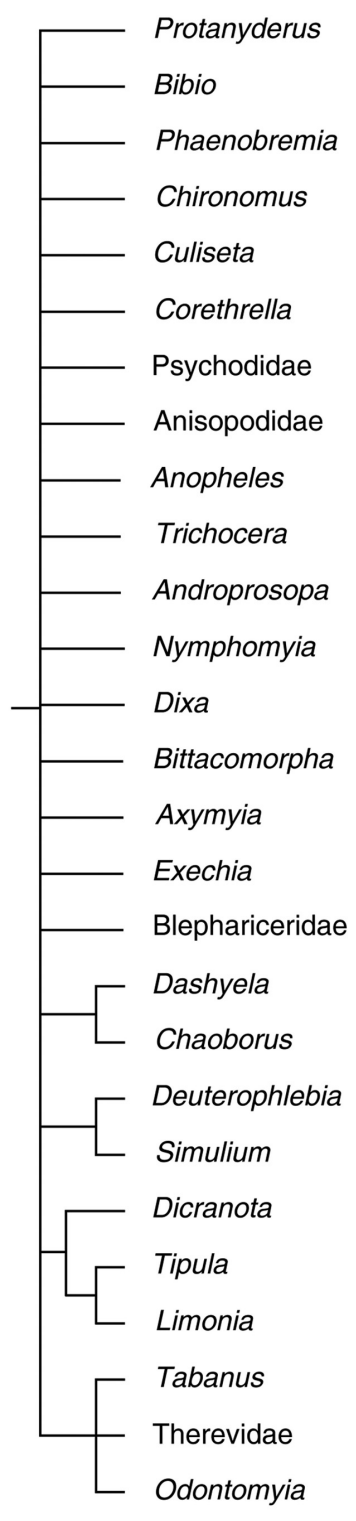

C

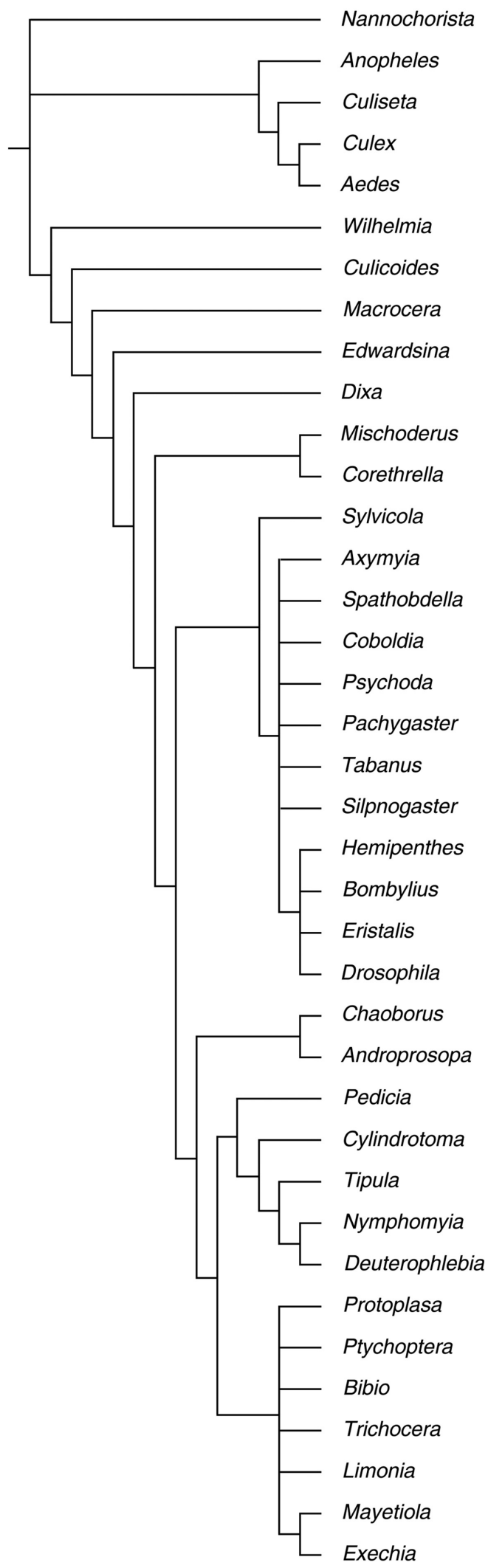

Figure 1. Strict consensus trees based on: $\mathrm{A}$, the complete data set $(\mathrm{Cl} 0.33, \mathrm{RI} 0.29)$. B, larval head structures $(\mathrm{Cl} 0.26$, $\mathrm{RI} 0.21)$. $\mathrm{C}$, adult

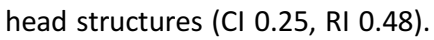




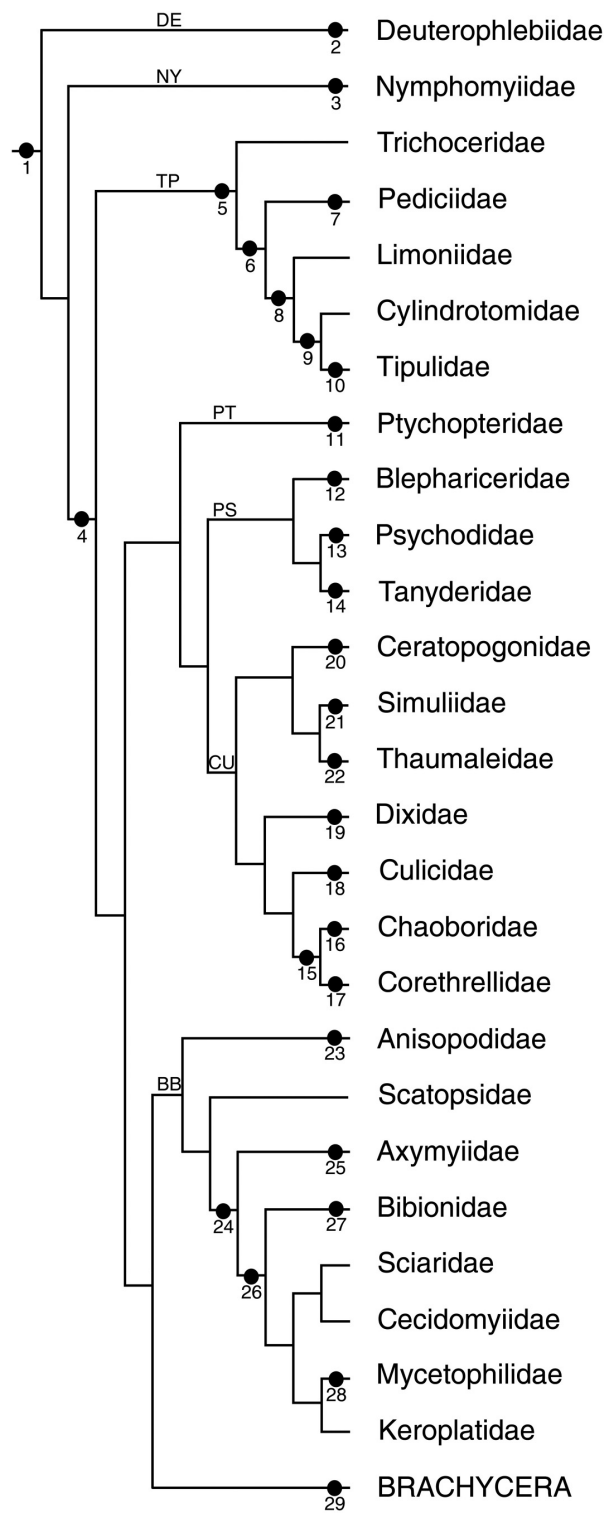

Figure 2. Characters mapped on the cladogram of Wiegmann et al. [23, Figure 1]. potential apomorphies indicated by black points. 1, Diptera: Adult head: dense vestiture of microtrichia, presence of a clypeolabral muscle, reduction of the postmentum, transformation of the labial palps into labellae (equipped with simple furrows). Larval head: labrum equipped with a dense field of hairs, presence of a hypostoma (hypostomal bridge) with triangular teeth. 2, Deuterophlebiidae: Adult head: antenna inserted laterally, widely separated, last antennal segment extremely elongated, labrum, maxilla, and labium reduced (inclusive associated muscles), reduction of M. tentoriobuccalis anterior and M. hypopharyngosalivarialis. Larval head: presence of externolateral plates with growth lines (homoplasious character), labral brush consists of macrosetae, reduction of $\mathrm{M}$. labroepipharyngalis, bifurcate distal antennal segment, presence of apical multitoothed mandibular comb (homoplasious character), largely membranous cardo. 3, Nymphomyiidae: Adult head: completely sclerotized rostrum, club-shaped antenna with enlarged first and elongated terminal segment, completely reduced tentorium, reduction of labrum, maxilla, and labium (inclusive associated muscles), loss of M. tentoriobuccalis (homoplasious character). Larval head: completely reduced tentorium, labral brush consisting of macrosetae, reduction of $\mathrm{M}$. labroepipharyngalis, bifurcate distal antennal segment, presence of an apical multitoothed mandibular comb. 4, Diptera, exclusive Deuterophlebiidae and Nymphomyiidae: Larval head: loss of M. tentoriostipitalis, presence of a pharyngeal filter. 5, Tipulomorpha: Adult head: sensilla on sensorial field of third maxillary palpomere exposed on surface (homoplasious character). Larval head: deep ventromedian incisions of the head capsule. 6, Tipuloidea: Adult head: stipites partly fused. Larval head: presence of paired dorsolateral incisions, presence of growth lines on the extensive externolateral plates (homoplasious character). 7, Pediciidae: Larval head: mandible elongated and sickle-shaped, distinctly elongated maxillary palpomere. 8, Tipuloidea, exclusive Pediciidae: Larval head: head strongly retracted and fixed in this position, presence of premaxillary suture 
Chaoboridae with Ceratopogonidae. Large parts of the tree are unresolved.

\section{Potential apomorphies of dipteran clades (Character mapping is based on Wiegmann et al. [23], Figure 2). For the adult and larval head muscle homologization see Appendices 4 and 5}

Deuterophlebiidae (Deuterophlebia). The antennae of adults are inserted laterally, widely separated, and the last antennal segment is extremely elongated. All mouthparts (labrum, maxilla, mandible, and labium) and associated muscles are completely absent. M. tentoriobuccalis anterior and M. hypopharyngosalivarialis are absent. Externolateral plates with growth lines are present in larvae of Deuterophlebia. The labral brush consists of macrotrichia. M. labroepipharyngalis is absent. The distal antennal segment is bifurcated (Figure 3A), and an apical multitoothed mandibular comb is present. The cardo is largely membranous.

Nymphomyiidae (Nymphomyia). The rostrum is completely sclerotized. The club-shaped antenna bears an enlarged first and an elongated terminal segment. Labrum, maxilla, mandible, and labium and their muscles are completely reduced. M. tentoriobuccalis is absent. The tentorium is completely reduced in adults and larvae. $M$. labroepipharyngalis is absent in the larval head. The labral brush consists of macrosetae and the mandible bears a multitoothed comb on the apex. The distal antennal segment is bifurcated (Figure 3B).

Diptera (excluding Deuterophlebiidae and Nymphomyiidae). The pharyngeal filter and the absence of M. tentoriostipitalis are potential larval apomorphies of Diptera excluding Deuterophlebia and Nymphomyia.

Tipulomorpha (Trichocera, Pedicia, Limonia, Cylindrotoma, and Tipula). The sensilla on the sensorial field of maxillary

and side plates (homoplasious character). 9, Tipulidae + Cylindrotomidae: Adult head: entirely sclerotized rostrum (homoplasious character). Larval head: movable lacinia mobilis (homoplasious character). 10, Tipulidae: Adult head: completely reduced tentorium and maxillary endites, sensilla on sensorial field of third maxillary palpomere inserted in individual grooves (homoplasious character), absence of the dorsal labial concavity (homoplasious character), presence of pseudotracheae (homoplasious character). Larval head: subdivided labrum, secondary mandibular joint shifted posterior to antennal foramen. 11, Ptychopteromorpha: Adult head: sensilla on sensorial field of third maxillary palpomere exposed on surface (homoplasious character), presence of pseudotracheae (homoplasious character). Larval head: subdivided mandible (distal part separated by a furrow), hypostomium present as separate structure (homoplasious character). 12, Blephariceridae: Adult head: completely fused stipites, absence of furrows on internal side of labellae (homoplasious character). Larval head: presence of externolateral plates with growth lines (homoplasious character). 13, Psychodidae: Adult head: M. tentorioscapalis anterior bipartite with one subcomponent originating on the tentorium and one on the head capsule, foursegmented maxillary palp (homoplasious character), loss of M. palpopalpalis maxillae primus. 14, Tanyderidae: Adult head: M. tentoriostipitalis originates on head capsule. Larval head: presence of premaxillary suture and side plates (homoplasious character), specific arrangement of labral brush, hypostomium present as separate structure (homoplasious character). 15, Chaoboridae + Corethrellidae: Adult head: absence of furrows on internal side of labellae (homoplasious character). Larval head: antennal insertion shifted close to the midline. 16, Chaoboridae: Larval head: U-shaped frons (homoplasious character), presence of simplified compound eyes, presence of movable lacinia mobilis (homoplasious character). 17, Corethrellidae: Adult head: sensilla on the sensorial field of third maxillary palpomere inserted in individual grooves (homoplasious character). Larval head: antenna with two apical horns. 18, Culicidae: Adult head: joint between clypeus and frons, subdivision of clypeus, fulcrum, labroepipharyngeal food channel closed by sides of epipharynx, loss of M. labroepipharyngalis (homoplasious character), internalized stipites. 19, Dixidae: Larval head: median division of hypostomium. 20, Ceratopogonidae: Larval head: U-shaped frons (homoplasious character). 21, Simuliidae: Adult head: loss of M. labroepipharyngalis (homoplasious character), internalized stipites (homoplasious character). Larval head: triangular median membranous sinus of head capsule, absence of anterior tentorial arms (homoplasious character). 22, Thaumaleidae: Adult head: loss of M. stipitopalpalis externus. Larval head: apical multitoothed mandibular comb (homoplasious character). 23, Anisopodidae: Adult head: sensilla of the sensorial field of the third maxillary palpomere inserted in individual grooves (homoplasious character). Larval head: presence of strongly sclerotized labral teeth, presence of an anteriorly directed cone on the mesal mandibular edge, subdivided mandible (distal part separated by a furrow). 24, Bibionomorpha, excluding Anisopodidae and Scatopsidae: Adult head: absence of the concavity on the dorsal surface of the anterior labium (homoplasious character). Larval head: absence of anterior tentorial arms (homoplasious character). 25, Axymyiidae: Adult head: subdivided compound eyes, loss of M. hypopharyngosalivarialis. Larval head: head moderately retracted (homoplasious character), presence of a secondary frontoclypeal ridge (probably not homologous with that of other insects), subdivided clypeus. 26, Bibionomorpha, exclusive Anisopodidae, Scatopsidae, and Axymyiidae: Larval head: reduction or complete fusion of maxillary endite lobes. 27, Bibionidae: Adult head: absence of vestiture of microtrichia (head covered with long setae), antennae inserted laterally. Larval head: loss of M. frontoepipharyngalis, hypostomium present as separate structure (homoplasious character). 28, Mycetophilidae: Adult head: partly hollow anterior tentorial arm, four-segmented maxillary palp (homoplasious character). 29, Brachycera: Adult head: reduced number of antennomeres and maxillary palp segments, presence of pseudotracheae on the internal side of the labellae. Larval head: loss of extrinsic antennal muscles, cibariopharyngeal sclerotization. 

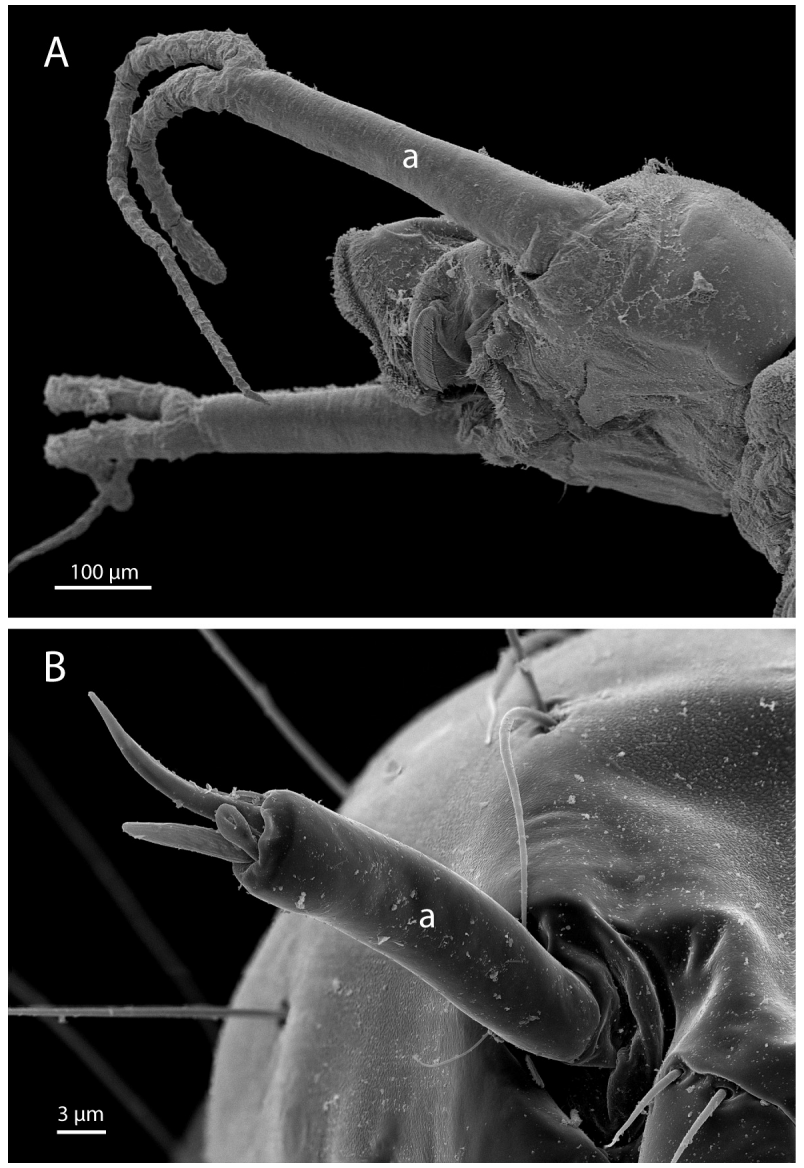

Figure 3. Larval antenna, SEM images. A, Deuterophlebia coloradensis (Deuterophlebiidae), lateral. B, Nymphomyia dolichopeza (Nymphomyiidae), frontal. Abbreviation: a, antenna.

palpomere 3 are exposed on the surface. The larval head is characterized by deep ventromedian incisions.

Tipuloidea (Pedicia, Limonia, Cylindrotoma, and Tipula). The stipites are partly fused in the members of Tipuloidea examined. In larvae the head is partly divided by paired dorsolateral incisions. Growth lines are present on the extensive externolateral plates.

Pediciidae (Pedicia). The mandible of the larvae is sickleshaped and elongated. The maxillary palpomere is also distinctly elongated.

Tipuloidea (exclusive Pediciidae). Tipuloidea, excluding Pediciidae, are characterized by a larval head that is strongly retracted into the prothorax and fixed in this position. A premaxillary suture and side plates are present.

Tipulidae (Tipula) + Cylindrotomidae (Cylindrotoma). The rostrum of adults of Tipula and Cylindrotoma is entirely sclerotized, and the larval mandible bears a movable lacinia mobilis.

Tipulidae (Tipula). The tentorium and the maxillary endites are completely reduced. The sensilla on the sensorial field of maxillary palpomere 3 are inserted in individual grooves (e.g. Figure 4A, Sylvicola). A dorsal concavity of the prementum is absent. The labellae bear pseudotracheae on the inner surface (Figure 5B). In the larval head, the labrum is subdivided, and the secondary mandibular joint is shifted posterior to the antennal foramen.

Ptychopteromorpha (Ptychoptera). The sensilla on the sensorial field of maxillary palpomere 3 are exposed on the surface in Ptychoptera (e.g., Figure 4A, Sylvicola). Pseudotracheae are present on the inner surface of the labellae. The larval mandible is subdivided, and the hypostomium is present as a separate structure.

Blephariceridae (Edwardsina). In Edwardsina, the stipites are completely fused. The furrows on the inner surface of the labellae are completely missing. Growth lines are present on the externolateral plates in blepharicerid larvae.

Psychodidae (Psychoda). M. tentorioscapalis is bipartite in adults of Psychoda. One subcomponent originates on the tentorium and one on the head capsule. The maxillary palp is four-segmented. M. palpopalpalis primus is missing.

Tanyderidae (Mischoderus and Protanyderus). M. tentoriostipitalis originates on the head capsule. The larval head is characterized by a premaxillary suture, and side plates are present.
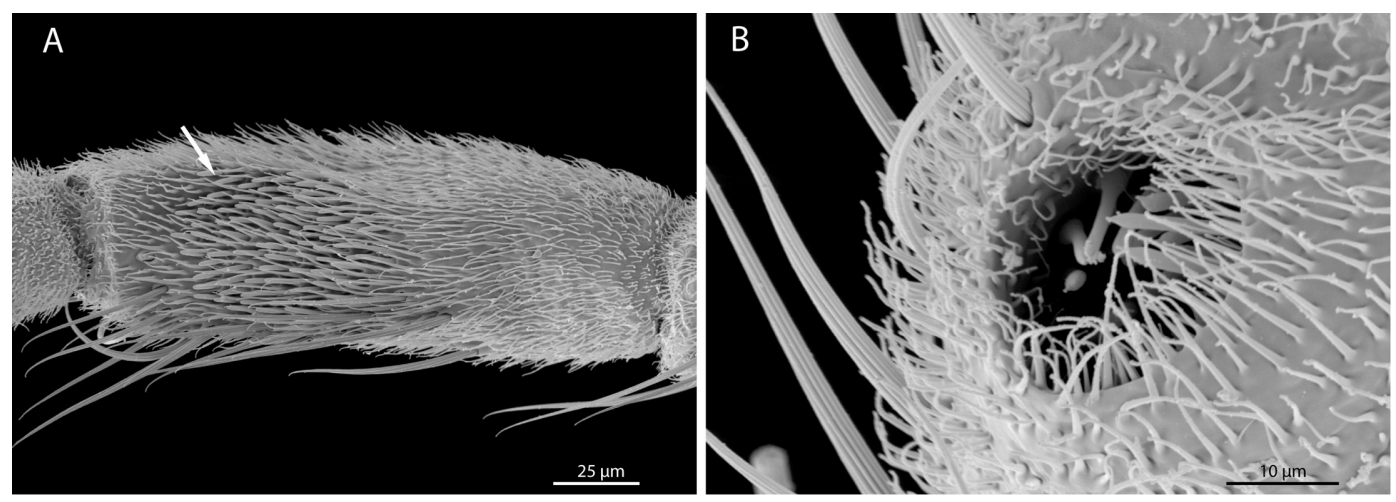

Figure 4. Sensorial field on maxillary palpomere 3, SEM images. A, Sylvicola fenestralis (Anisopodidae), ventral. B, Edwardsina gracilis (Blephariceridae), ventral. 

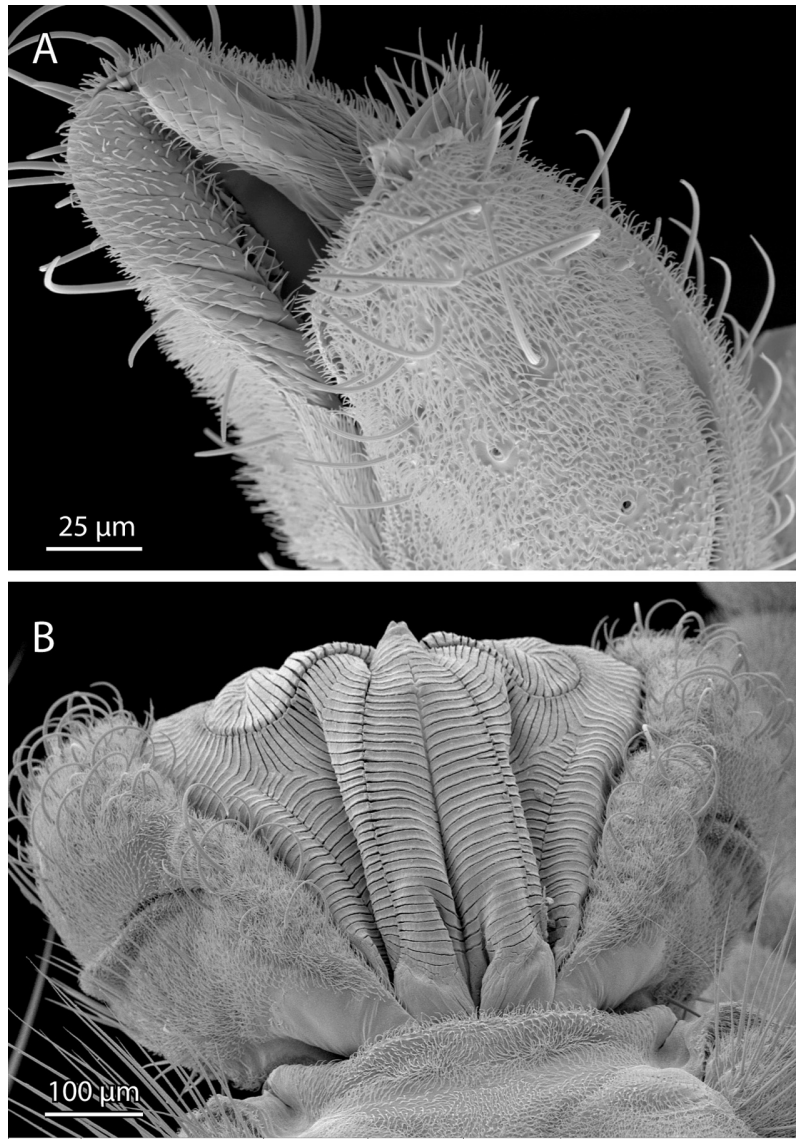

Figure 5. Labellae, SEM images. A, Aedes sp. (Culicidae), frontal. B, Tipula paludosa (Tipulidae), dorsal.

The larval labrum bears a brush with specifically arranged setae. The hypostomium is present as a separate structure. Chaoboridae (Chaoborus) + Corethrellidae (Corethrella). In adults of Chaoborus and Corethrella, the furrows on the inner surface of the labellae are completely missing. The larval antennae insert on the anterior margin of the head and are shifted close to the midline (Figure 6).

Chaoboridae (Chaoborus). Larvae of Chaoborus have simplified compound eyes and their frons is U-shaped. A movable lacinia mobilis is present on the mandible. A small intrinsic extensor muscle moving the lacinia mobilis is present.

Corethrellidae (Corethrella). In adults, the sensilla on the sensorial field of the maxillary palpomere 3 are inserted in individual grooves. The larval antenna bears two apical horns in Corethrella (Figure 6B, a)

Culicidae (Aedes, Anopheles, Culex, and Culiseta). Clypeus and frons are connected by a joint in all members of Culicidae examined (Figure 7). The clypeus is subdivided, and a fulcrum is developed. The labroepipharyngeal food channel is closed by the sides of the epipharynx. The stipites are completely internalized (cryptostipites after Peterson [41]). M. labroepipharyngalis is absent.
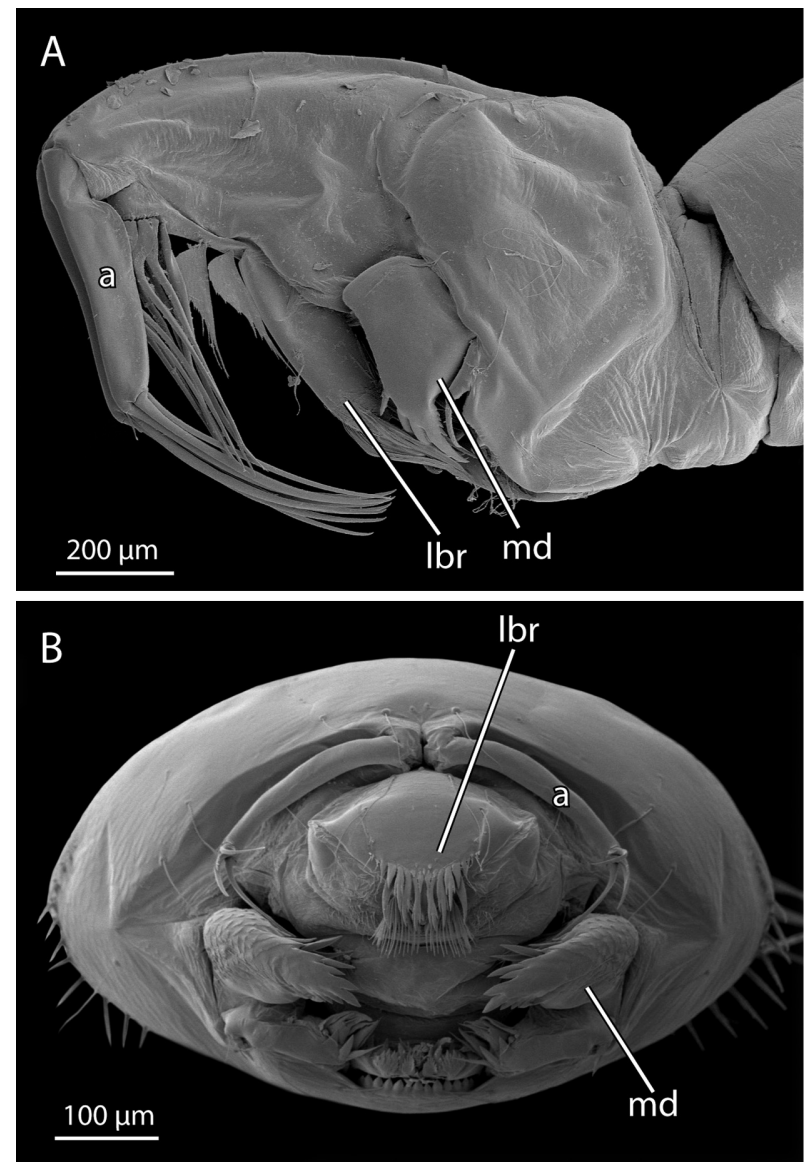

Figure 6. Head capsule, SEM images. A, Chaoborus christallinus (Chaoboridae), lateral. B, Corethrella appendiculata (Corethrellidae), frontal. Abbreviations: a, antenna; Ibr, labrum; md, mandible.

Dixidae (Dixa). The hypostomium of larvae of Dixa is medially subdivided.

Ceratopogonidae (Culicoides). The larval frons is U-shaped.

Simuliidae (Wilhelmia and Simulium). The stipites are internalized in adults of Wilhelmia, and M. labroepipharyngalis is absent. Anterior tentorial arms are completely missing in larvae of Simulium, and the head capsule bears a triangular median membranous sinus.

Thaumaleidae (Androprosopa). M. stipitopalpalis is absent. The larval mandible bears a multitoothed comb.

Anisopodidae (Sylvicola). In adults, the sensilla on the sensorial field of maxillary palpomere 3 are inserted in individual grooves (Figure 4A). In larvae strongly sclerotized labral teeth are present. The mandible is subdivided, and an anteriorly directed cone is inserted on the mandibular edge.

Bibionomorpha (exclusive Anisopodidae and Scatopsidae). Adults lack the dorsal concavity on the surface of the anterior labium. Anterior tentorial arms are completely missing in larvae. Axymyiidae (Axymyia). The compound eyes of adults are subdivided into a dorsal and a ventral part. The salivary pump 


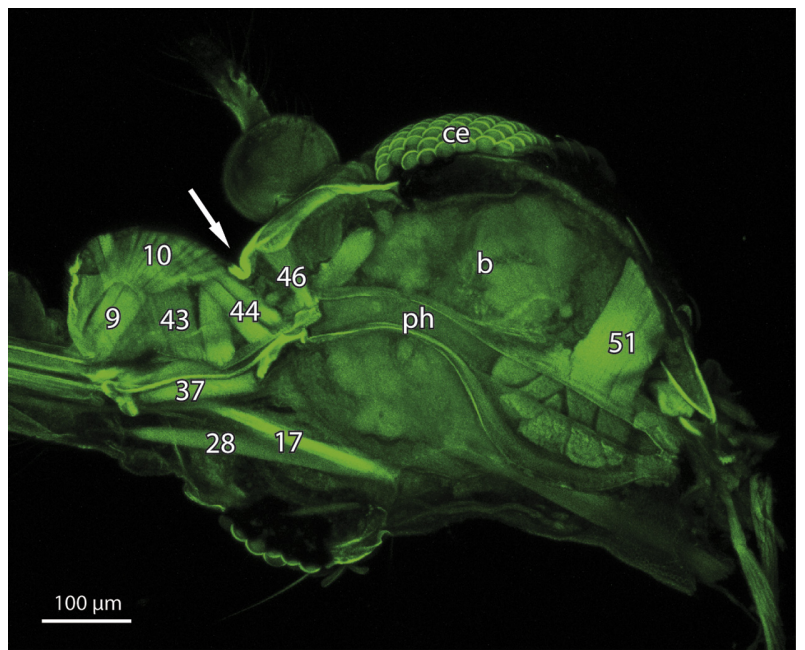

Figure 7. Culex pipiens (Culicidae), sagital section, CLSM image. Arrow: joint between frons and clypeus. Abbreviations: $b$, brain; ce, compound eye; ph, pharynx; 9, M. frontoepipharyngalis; 10, M. epistomalabralis; 17, M. tentoriocardinalis; 28, premental retractor; 37, M. hypopharyngosalivarialis; 43, M. clypeopalatalis; 44, M. clapeobuccalis; 46, M. frontobuccalis posterior; 51, M. verticopharyngalis.

musculature (M. hypopharyngosalivarialis) is completely absent. The larval head is moderately retracted into the prothorax but not fixed in this position. The larval clypeus is subdivided, and a secondary frontoclypeal ridge is present (probably not homologous with that of other insects).

Bibionomorpha (exclusive Anisopodidae, Scatopsidae and Axymyiidae). The larval maxillary endites are completely reduced.

Bibionidae (Bibio). The adult head capsule is covered with long setae, and the dense vestiture of microtrichia is absent (Figure 8D). The antennae are inserted laterally. The larval hypostomium is present as a separate structure and M. frontoepipharyngalis is reduced.

Mycetophilidae (Exechia). In adults, the anterior tentorial arm is partly hollow and the maxillary palp is four-segmented.

Brachycera (Tabanus, Pachygaster, Silpnogaster, Bombylius, Hemipenthes, Eristalis, and Drosophila). The number of antennomeres and maxillary segments is reduced in the examined brachyceran species. Pseudotracheae are present on the inner surface of the labellae. The larvae are characterized by a cibariopharyngeal sclerotization, and extrinsic antennal muscles are missing.

\section{DISCUSSION}

\section{Phylogeny}

The analysis of adult and larval head structures revealed a considerable number of potential dipteran autapomorphies. The relationships of the basal lineages, which were the main target of the cladistic character evaluation, were not well resolved, especially using only characters of the adult head
(Figure 1C). The consistency index (CI) of trees based on the separate adult character set is low (CI 0.25, retention index [RI] 0.48) and only slightly higher in the analyses of the combined data set (CI 0.33, RI 0.29 Figure $1 \mathrm{~A}$ ) and analyses of larval head structures (CI 0.26, RI 0.21 (Figure 1B). Commonly accepted clades were not recovered in the analyses of adult head structures. Diptera was rendered paraphyletic in this analysis, with the mecopteran family Nannochoristidae nested within the order (Figure 1C). In the analyses of larval head structures Diptera is monophyletic and also Tipuloidea and Brachycera. The same clades were confirmed in the combined analyses.

Characters of the adult head are not only relatively conservative within the order but also greatly affected by homoplasy, especially parallel losses (e.g., antennal segments, mandibles, and muscles). This may be due to the relatively similar life style of adult dipterans belonging to different lineages. Apparently, adult head structures alone are unsuitable for reconstructing the intraordinal relationships, even though dramatic character transformation must have taken place in the dipteran stem-group (e.g., modifications of the mouthparts), and some very characteristic features evolved within the group (e.g., labellae, pseudotracheae, and aristate antennae in Brachycera). The larvae differ much more in their habitats, general life style, and feedings habits, and not surprisingly also in their head structures. The absence of the thoracic legs is arguably a key feature of dipteran larvae and no variation occurs within the group in this feature. In contrast to that, cephalic structures can vary dramatically, reaching from well-developed heads with functioning complex mouthparts, antennae composed of several segments, distinct light sense organs, endoskeletal structures, and a complex muscle system, to strongly retracted simplified heads (e.g., Tipulomorpha; [27]) or largely reduced and highly specialized head structures as they are characteristic for most groups of Brachycera (Cyclorrhapha; e.g., [33]). Despite of a strong variation within the group, characters of the larval head, like those of the adults, are not sufficient for resolving basal dipteran relationships. Analyses of larval feature are also strongly affected by homoplasy, especially parallel reductions, which affected sense organs, mouthparts, the external head structures, the endoskeleton, and also the muscle system.

Resolving intraordinal relationships in Diptera using morphology is likely impeded by episodic bursts of rapid radiation. This took place in the early Mesozoic (stem-group), Triassic (lower dipteran groups) (220 Ma), in the early Jurassic (lower Brachycera) (180 Ma), and in the early Paleocene (lower Brachycera) (65 Ma) [23, 42])

\section{Phylogenetic implications of the examined characters}

Diptera. Diptera is monophyletic in the analyses of the combined and larval characters (Figure 1A, B) but not in the analyses of adult head features (Figure 1C). Potential autapomorphies are the dense vestiture of microtrichia on 

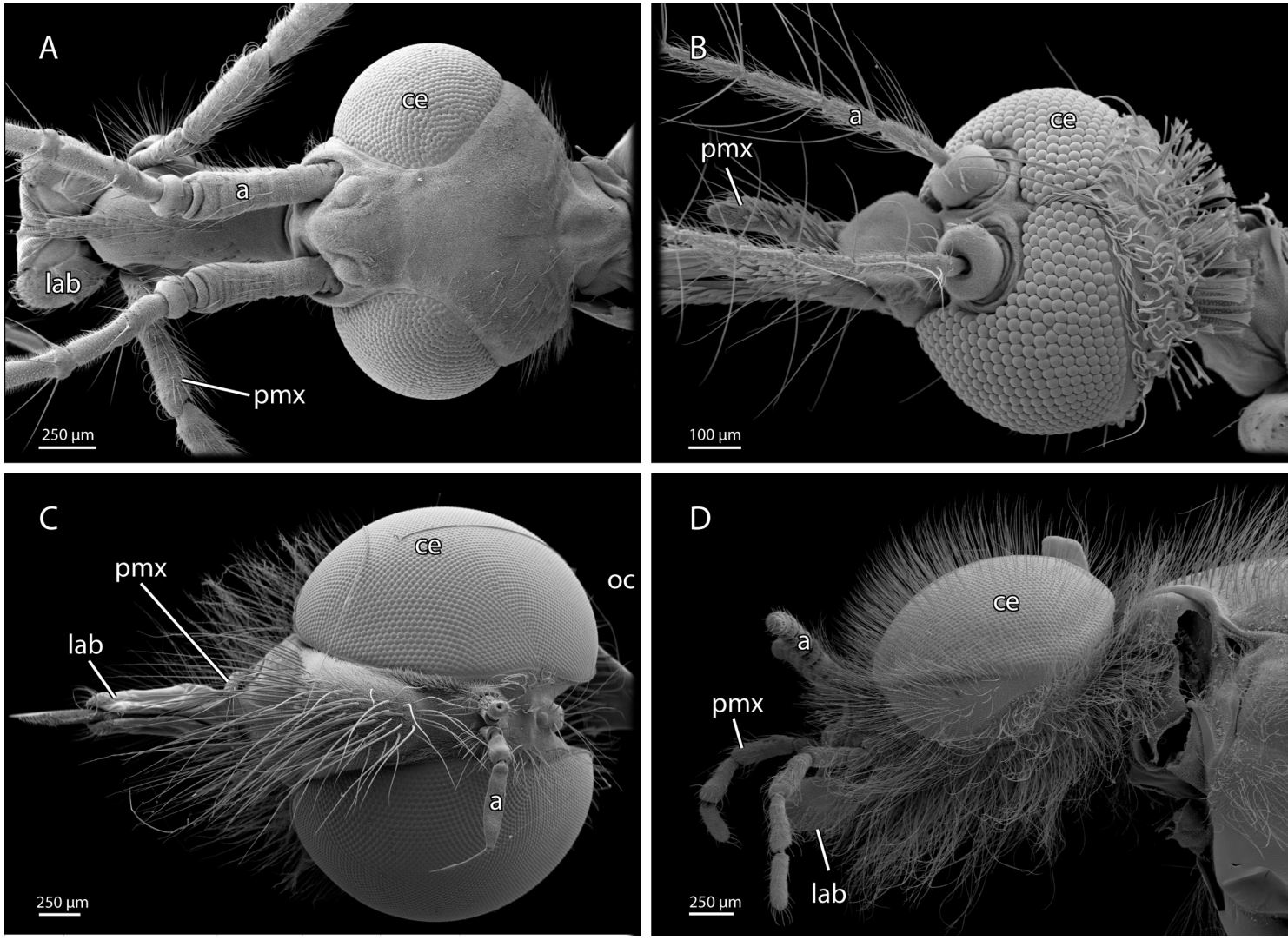

Figure 8. Head capsule, SEM images. A, Tipula paludosa (Tipulidae), dorsal. B, Culex pipiens (Culicidae), laterodorsal. C, Silpnogaster aemula (Asilidae), dorsal. D, Bibio sp. (Bibionidae), lateral, copyright Hans Pohl. Abbreviations: a, antenna; ce, compound eye; lab, labella; oc, ocelli; pmx, maxillary palp.

the head (Figure $8 \mathrm{~A}-\mathrm{C}$ ), the reduction of the postmentum, the two-segmented labial palps transformed into labellae (equipped with simple furrows), and the presence of a clypeolabral muscle.

A groundplan apomorphy of the larval head is a labrum equipped with a dense field of hairs (Figure 6B). The presence of a larval hypostoma (= hypostomal bridge) with triangular teeth is most likely a groundplan apomorphy of Diptera, a condition found in most groups of lower Diptera.

Deuterophlebiidae + Nymphomyiidae. Deuterophlebiidae and Nymphomyiidae are sistergroups according to Cutten \& Kevan [43], and this is also suggested by the analyses of the data presented here (adult head and complete data set; Figure 1A, C). Cutten \& Kevan [43] suggested the presence of lateral eyespots of older larvae, the anteriorly projecting larval rostrum, the presence of abdominal prolegs, and a pair of appendages on the larval abdomen as potential synapomorphies. The studies of Schneeberg et al. [28] and Schneeberg et al. [29] also suggested close phylogenetic affinities between the two groups.

Both families share a large number of derived features of the adult head. In both groups the labrum, maxillae, and labium are completely missing including their extrinsic and intrinsic muscles. M. tentoriobuccalis anterior (M. 48) is completely reduced and the terminal antennal segment is distinctly elongated [28].

Larval features supporting this hypothesis are the presence of rows of spatulate macrosetae on the ventral surface of the labrum-epipharynx (only in later-instar larvae in Deuterophlebiidae) [29, 44]. The labrum is completely fused with the head capsule in the larvae, accompanied by the loss of M. labroepipharyngalis (M. 7) and M. frontolabralis (M. 8), a condition also occurring in some groups of Brachycera, and in Cecidomyiidae and Simuliidae [45-48]. Another potential synapomorphy is the apical multitoothed mandibular comb. The comb is also present in larvae of Thaumaleidae and some species of Blephariceridae [16], which is likely the result of parallel evolution.

Other similarities concerning the morphology and life history were pointed out by Courtney [44]. The females shed their wings after or during oviposition, the femora and tibiae are subdivided by a membranous zone, and all abdominal spiracles and the spermatheca are reduced. Courtney [44] interpreted all shared similarities as convergencies, related to the short live span of adults. This interpretation is supported by the comprehensive molecular study of Wiegmann et al. [23], 
where a clade Nymphomyiidae + Deuterophlebiidae was not confirmed (see below).

Deuterophlebiidae and Nymphomyiidae are both highly specialized in their morphology and life style and doubtlessly monophyletic [28, 44]. Autapomorphic features of Deuterophlebiidae are prolegs with curved crochets with five teeth, five anal papillae, Malpighian tubules attached to anal papillae, a prehardened pupal cuticle, a male pretarsus densely set with capitate microtrichia, and reduced tarsal claws $[48,49]$. Apomorphies of the head are the widely separated antennal insertions, an extremeley elongated apical flagellomere of males, M. tentorioscapalis anterior (M. 1) with multiple areas of origin, and the absence of M. hypopharyngosalivarialis (M. 37) [28]. Possible larval apomorphies are the growth lines on the externolateral plates (see also [49]), the fusion of clypeus and frons, the bifurcate distal antennal segment (Figure 3A), and the largely membranous cardo.

Autapomorphies of Nymphomyiidae are the dimorphic larval crochets, Malpighian tubules originating on a common stalk on the ventral gut surface, and the prognathous head of the pupa. The narrow wings are strongly modified and shed after flight or during oviposition. They are characterized by a marginal fringe of elongate macrotrichia, a poorly developed anal lobe, reduced posterior veins, and anterior veins concentrated along the costal margin. Other potential autapomorphies suggested by Courtney [49] are the neotenic adults, an anterolateral angle of abdominal tergite VIII equipped with prominent tubercles, subdivided femora and tibiae, missing abdominal spiracles, and the reduced spermatheca.

Characters of the adult head are the ventrally contiguous compound eyes, the loss of the unpaired ocellus, the shift of the paired ocelli posterior to the compound eyes, the completely sclerotized rostrum, the club-shaped antenna, and the strongly enlarged first antennal flagellomere [50].

Tipuloidea. Tipuloidea (= Tipulomorpha, excl. Trichoceridae) was consistently confirmed as monophyletic in the previous studies, but a close relationship with Trichoceridae was discussed controversially. Wood \& Borkent [9] suggested an inclusion of Trichoceridae in Psychodomorpha mainly based on larval characters. Tipulomorpha (including Trichoceridae) was also rejected as a clade in some morphological studies [e.g., 21, 51, 52]. In contrast, it was supported in a considerable number of older and more recent studies, based on morphological characters of larvae and adults (including or excluding extinct taxa) $[8,14,16,24,53-56]$ or molecular data $[20,23]$. This concept was also supported in a recent study focused on dipteran attachment structures [57]. The analyses suggest that an arolium was secondarily acquired in Tipulomorpha inclusive Trichoceridae. It is missing in all other groups of Diptera.

Tipuloidea is supported in the complete analyses and in the analyses of larval head structures (Figure 1A, B). Trichoceridae is not placed as the sister group of this clade.
An apomorphic character of Tipuloidea is the partial fusion of the stipites in adults. This groundplan feature is found in Pedicia and in Limonia, whereas the stipites are completely fused in Tipulidae [58]. A partial fusion also occurs in Sciaridae and Scatopsidae, apparently the result of parallel evolution. Other shared derived characters of Tipuloidea are the absence of M. craniolacinialis (M. 19) and the presence of only one muscle of the precerebral pharyngeal pump, but both characters also occur in several other dipteran groups $[28,58,59,60]$. The anterior tentorial arm is a thick hollow tube in the dipteran groundplan, as it is the case in most species examined. The anterior arm is massive in most groups of Tipuloidea (entire anterior arm in Pedicia and in Cylindrotoma, anterior part in Limonia; see [58]). Similar conditions have evolved independently in Syrphidae and in some members of Bibionomorpha.

The head capsule of tipuloid larvae is separated from the dorsomedian fragment by paired dorsolateral incisions [27, 46, $61,62]$. This is another potential autapomorphy of the group. A similar condition is present in Liponeura but is absent in other members of Blephariceridae [63]. Another apomorphic character is the presence of growth lines (zonal structures as intermold cuticle depositions) on the extensive externolateral plates [27, 62, 64]. A similar condition has probably evolved independently in larvae of Deuterophlebiidae, Blephariceridae, and Tanyderidae $[16,32,48]$. The hypostoma of tipuloid larvae is partly (Pediciidae; [46]) or completely divided (Limoniidae, Tipulidae; $[27,65]$ ). It is undivided in the dipteran groundplan, as it is the case in almost all examined dipteran larvae (with the exception of Dixidae; [66]). The partial division is likely a transitional state between the undivided hypostoma in the groundplan of the order and the complete division in Tipulidae and in Limoniidae.

Brachycera. Brachycera are supported by the combined data set (Figure 1A) and by larval features (Figure 1B), but surprisingly not in analyses of characters of the adult head (Figure 1C). The monophyly of Brachycera has never been questioned. They are supported by a broad spectrum of morphological characters of adults and larvae (e.g., thoracic or genital morphology) [e.g., 2, 8, 14, 16, 21] and also unambiguously by molecular data $[20,23,26]$.

The presence of only seven antennomeres is likely a derived groundplan feature of Brachycera. The number of antennomeres is also reduced in Deuterophlebia [28] and in Nymphomyia [50] but in both cases linked with a strong elongation of the distal segment. The reduction of the number of maxillary palpomeres is also an autapomorphy of Brachycera. The palps are two- or one-segmented in the examined species. Hesse $[67,68]$ described three-segmented palps for Bombyliidae, but this is probably due to reversal. A reduction of palpomeres is rare in the lower dipteran groups but occurs in some Culicidae, Cecidomyiidae, and Sciaridae $[30,69]$, apparently as a result of parallel evolution. Another apomorphic condition is the presence of pseudotracheae on 
the inner surface of the labellae of Brachycera. However, these structural modifications also occur in some groups of lower Diptera (Tipulidae, Ptychopteridae, and some Mycetophilidae; [58, 70]; Figure 5B).

An apomorphic character of brachyceran larvae is the mandibulo-maxillary complex, which is absent in all members of lower Diptera [e.g., 46, 71]. The larval mandible is subdivided into a distal and a basal part by a weakly sclerotized zone in all brachyceran larvae. This is a potential autapomorphy, even though a subdivision with a membranous zone is also present in larvae of Anisopodidae and Ptychopteridae, and both parts are separated by a furrow in pychopteran larvae $[45,72]$. Another larval autapomorphy is the presence of a complex structural unit with a trough-like, sclerotized ventral wall formed by the cibarium and pharynx [46]. This condition does not occur in lower Diptera [27, 29, 32, 44, 46, 72-76].

\section{Character transformations}

Wiegmann et al. [23] presented a robust phylogenetic tree based on molecular data from species of 149 families, including $30 \mathrm{~kb}$ from 14 nuclear loci and the complete mitochondrial genomes. This tree was used to develop an evolutionary scenario for adult and larval head structures.

Adult head. Head capsule. The head capsule is completely covered with microtrichia (apomorphy) in the dipteran groundplan. This condition is found in almost all dipteran taxa examined [e.g., 28, 30, 31, 50, 58], with the exception of Bibio (Bibionidae) and Pachygaster (Stratiomyiidae) (Figure $8)$. The characteristic vestiture is also missing in other groups of Bibionidae [77], apparently due to secondary loss. In both families, the microtrichia are replaced by longer setae (Figure 8D). Adults of species of both groups visit flowers and a possible function of the longer setae on the head and other body parts is to keep the pollen from the cuticular surface [78, 79]. In Nannochorista, the head capsule is also covered with very short and fine hairs [80], but this condition differs strongly from what is usually found in dipterans. Microtrichia are absent in other groups of Mecoptera [81, 82] and also in Siphonaptera [83]. A dense vestiture of microtrichia on the head capsule has evolved independently in Strepsiptera [84] and some members of Heteroptera [e.g., 85, 86]. The microtrichia are the only shared derived cephalic character of Diptera and Strepsiptera identified in the present study. This is apparently a result of convergency. In contrast to studies based on ribosomal genes (e.g., [87]: Halteria hypothesis) Strepsiptera are now unambiguously placed as a sistergroup of Coleoptera and both are nested within a more inclusive group Neuropteroidea [88-91, 105]. It is likely that the resulting surface properties improve the flight performance of dipterans as it is the case in Strepsiptera (H. Pohl, pers. comm.). The adult head is orthognathous in the dipteran groundplan and in most taxa examined, whereas it is prognathous in Tipulomorpha [58], Nymphomyiomorpha [50],
Ptychopteromorpha, and most members of Culicomorpha (partim, not in Simuliidae and in Ceratopogonidae) [41]. The head of Mecoptera (with the exception of Nannochorista) [80, 81, 82] and Siphonaptera [83] is also orthognathous, indicating that this is a groundplan feature of Antliophora. Prognathism is possibly partly linked with the development of a rostrum, which is present in members of Tipulomorpha and Nymphomyiomorpha and some other groups (not in Ptychopteromorpha).

Whether a rostrum is present in the groundplan of Diptera is ambiguous as it is missing in Deuterophlebiidae and many other groups of lower Diptera. If present, it is usually only sclerotized on the dorsal side in the lower dipteran families, arguably a plesiomorphic condition. A completely sclerotized rostrum has evolved in Nymphomyiidae and in the tipulomorph clade Cylindrotomidae + Tipulidae, and in contrast a completely membranous rostrum in Anisopodidae and independently in Brachycera. The membranous condition is a characteristic and probably autapomorphic feature of the latter groups. The membranous rostrum is probably an adaptation to feeding on nectar and other liquid substances [e.g., 92, 93].

In the groundplan and all examined species of Brachycera, the clypeus and labrum are separated by the rostral membrane (haustellum). It ensures a high degree of movability, which facilitates flower-probing movements of the rostrum and its retraction in a resting position [93]. A separation of the sclerites by a membrane also occurs in some groups of lower Diptera, i.e., Tipulomorpha, Tanyderidae, Ptychopteridae, Bibionidae, Mycetophilidae, and Simuliidae $[58,94,95]$, arguably a result of parallel evolution. Some of the species in question also feed on plant sap [e.g., 96], but the available data are insufficient for a reliable interpretation. A frontoclypeal suture is part of the dipteran groundplan. It is usually present in the lower dipteran lineages and in Brachycera [59, 60, 97, 98], but was apparently reduced independently in several groups (e.g., Deuterophlebiidae, Nymphomyiidae, Ptychopteridae, and Blephariceridae; [28, 50]). A unique apomorphic condition is found in Culicidae, a joint between the clypeus and frons $[8,59,99]$. This probably facilitates the insertion of the mouthparts prior to the bloodsucking process.

The presence of a coronal suture is plesiomorphic for Diptera and Brachycera, but it is absent in most groups (preserved in Culicidae, Chironomidae, Nymphomyiidae, and Drosophilidae; $[41,50,59,97,99,100])$. Whether the frontal apodeme is part of the dipteran groundplan is questionable, as it is missing in most taxa of lower Diptera (e.g., Deuterophlebiidae, Nymphomyiidae, Axymyiidae, and Brachycera; [28, 31, 50, 59, $60,97])$. This structure is also present in Nannochorista [80] (see above) but absent in other mecopteran groups [82] and in Siphonaptera [83].

Three ocelli are present on the vertex in the groundplan, as it is also the case in most other groups of insects [e.g., 101104]. They were reduced several times independently (e.g., 
most Culicomorpha, Tipuloidea, Keroplatidae, Mycetophilidae, and Cecidomyiidae; $[30,58,59]$ without a recognizable phylogenetic pattern. Within Brachycera, they are only preserved in Tabanus $[59,97,98]$.

The compound eyes are unusually large and undivided in the groundplan of the order. The subdivision into a dorsal and a ventral part is an autapomorphy of the controversial family Axymyiidae [31], which is placed in Bibionomorpha after Wiegmann et al. [23].

An unusual structure which has evolved in several groups is the fulcrum which is composed of lateral plates which join the external clypeal wall. The presence is probably an autapomorphy of Culicidae and of Tanyderidae, respectively, and it is also common in brachyceran groups [59, 60, 94, 97].

Peterson [41] postulated the presence of a postgenal bridge in the groundplan of Brachycera, but not as an ancestral feature of the entire order. Its presence in several families of lower Diptera (e.g., Deuterophlebiidae, Nymphomyiidae, Tipulidae, Axymyiidae, Bibionidae, and Sciaridae; [28, 30, 50, $58,70])$ rather suggests that it may be a dipteran groundplan feature. Hennig [8] discussed a possible correlation between the presence of a hypostomal bridge and the reduction of the tentorium.

Tentorium. A nearly complete tentorium is present in the groundplan but a massive tentorial bridge and fully developed dorsal arms are never present [41]. A complete tentorium was described for Simulium by Peterson [41] but was not found in any of the species examined in this study $[28,30,31,58]$. More or less far-reaching reductions occur in several lineages. The complete loss of the tentorium is autapomorphic for Nymphomyiidae and for Tipulidae, respectively. In Nymphomyiidae, this is probably a result of the extreme size reduction. The tentorium is a thick, hollow, and simple tube in most dipteran groups (e.g., Culicomorpha, Psychodomorpha, Ptychopteridae, and Deuterophlebiidae; $[28,58,59,95])$. Dorsal arms occur as short vestiges in some families but are completely reduced in many groups. Surprisingly distinct dorsal arms are present in Tabanus [98] and Pipunculus (Pipunculidae). As both groups are nested within Brachycera, this is likely a secondary condition and possibly autapomophic in both cases.

It is possible that the more or less far-reaching reduction of the tentorium is correlated with the diet of the adults. Many of them feed on liquid substances such as nectar, some prefer pollen grains and dried honeydew, and some are sucking blood or are predators $[96,106]$. In all cases biting, which creates strong mechanical forces, is not involved. For feeding on liquid substrates, a stabilization of the head capsule is not necessary, as it is the case in insects with typical orthopteroid mouthparts (see e.g., [104]) where the head capsule is strengthened by a well-developed and strongly sclerotized tentorium and a more or less continuous system of internal ridges. A distinct tendency to reduce the tentorium is apparent in Diptera, especially in groups feeding on liquid substances or pollen. However, a reliable interpretation of the functional and phylogenetic background would require more specific information on the adult feeding habits in different groups.

Labrum. A labroepipharyngeal food channel closed by the hypopharynx is part of the groundplan according to Hennig [8]. The food channel is indeed present in most dipteran groups, but it is ventrally open in most cases (e.g., Tipulomorpha, Psychodomorpha, and Bibionomorpha; Figure 9 [58]). Therefore, it appears more likely that a ventrally open channel is ancestral for the order. Its specific condition differs within the group. In Culicidae it is completely enclosed by the epipharyngeal wall $[59,99,100,107,108]$ and used for sucking blood. Correlated with the closure, M. labroepipharyngalis (M. 7) is missing in this family [59, 99, 100, 109]. Females of Simuliidae are also hematophagous but in contrast to Culicidae pool feeders. They generate wounds with their mandibles and ingest the collected blood [110]. Like in Culicidae, M. labroepipharyngalis (M. 7) is missing.

A clypeolabral muscle is present in most species of Diptera examined (autapomorphy) [e.g., 30, 31, 58-60, 95, 98-100, 109], but is missing in Pachygaster and Drosophila [111], and also in Deuterophlebiidae, and in Nymphomyiidae, which lack a labrum and are characterized by an extremely reduced cephalic musculature [28, 50]. According to Matsuda [112], the primarily paired muscle is fused and unpaired in the groundplan of the order (M. 62 in [112]). However, the muscle is paired in most groups of lower Diptera (e.g., Tipulomorpha, Ptychopteromorpha, Ceratopogonidae, Bibionidae, and Sciaridae; [58, 113]), which is most likely the ancestral condition. The muscle is probably homologous with M. frontolabralis (M. 8 [114]) of other insects but originates consistently on the clypeus in Diptera. Hennig [8] discussed the possibility, that the dipteran clypeus may contain parts of the frons, as precerebral pharyngeal dilators originate on this area in Drosophila [97, 111]. However, such a condition was not observed in other dipterans examined. M. frontoepipharyngalis (M. 9), which is present in the dipteran groundplan, is generally absent in Brachycera.

Antenna. According to Hennig [8], the ancestral dipteran antenna is composed of a scape, pedicel, and 14 flagellomeres. However, the number of antennomeres varies strongly among the groups of lower Diptera, from 5 in Nymphomyiidae [50] to 113 in some Psychodidae [8], and it is strongly reduced in the groundplan of Brachycera [59, 60, 97, 98]. Aside from the number of segments, the antenna is filiform and inserted frontally between the compound eyes in the dipteran groundplan [e.g., 30, 31, 41, 50, 58, 69] (Figure 8A, B). Closely adjacent antennal insertions on the frontal region are also found in Mecoptera (with the exception of Caurinus; [80-82, 115]). Widely separated antennal bases with a dorsal insertion have apparently evolved independently in Deuterophlebiidae and Bibionidae [28]. Interestingly, the antennae are distinctly different in these two groups, as they 
A

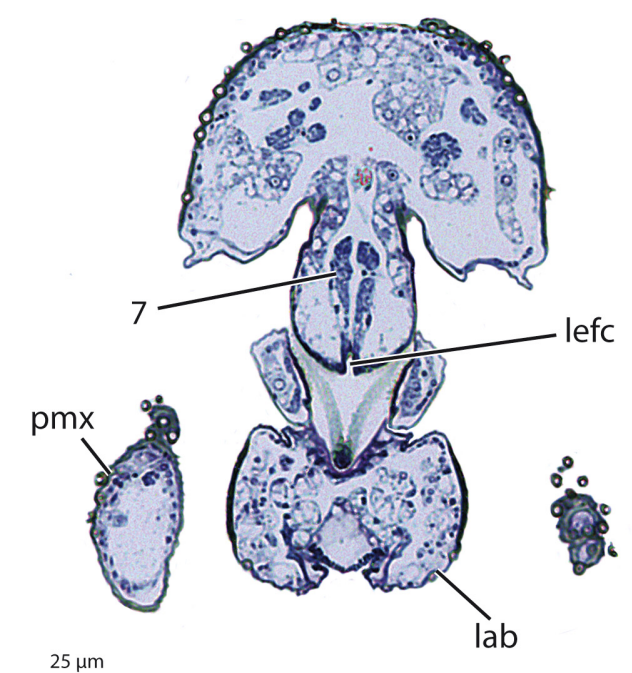

C

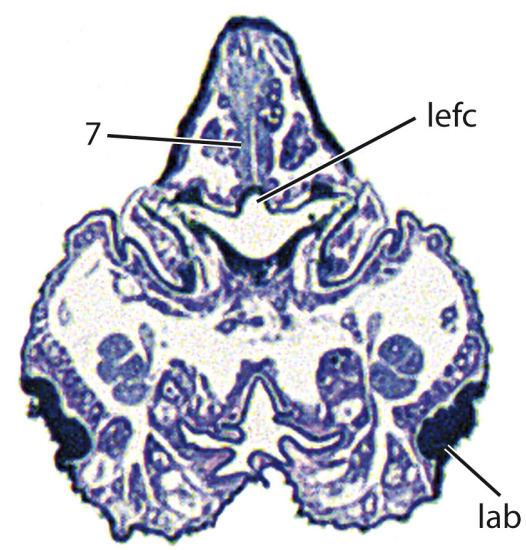

$100 \mu \mathrm{m}$
B

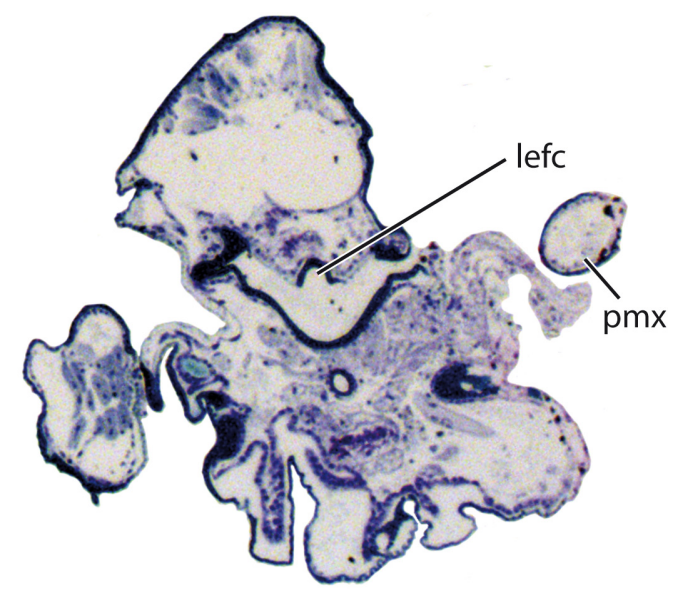

$100 \mu \mathrm{m}$

D

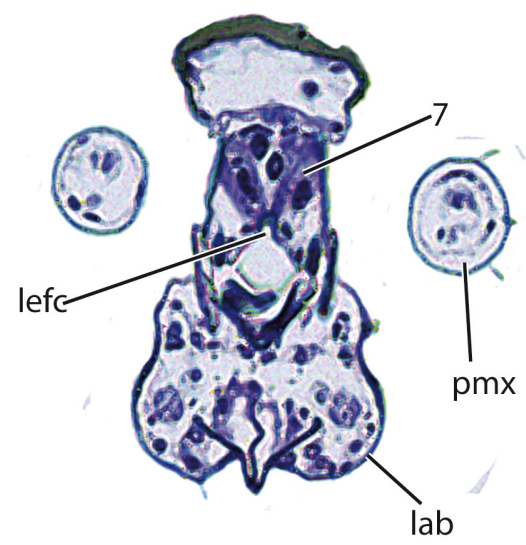

$25 \mu \mathrm{m}$

Figure 9. Cross-sections. A, Psychoda alternata (Psychodidae). B, Tipula paludosa (Tipulidae). C, Trichocera saltator (Trichoceridae). D, Corethrella appendiculata (Corethrellidae). Abbreviations: lab, labella; lefc, labroepipharyngeal food channel; pmx, maxillary palp; 7, M. labroepipharyngalis.

are elongated and slender in Deuterophlebiidae and moniliform and robust in Bibionidae (Figure 8D, a).

Moniliform antennae have evolved independently in Simuliidae and within Bibionomorpha in Bibionidae, Axymyiidae, and Scatopsidae [31]. Whether this is an apomorphy of Bibionomorpha, excluding Anisopodidae with reversal in a subgroup comprising Sciaridae, Cecidomyiidae, Keroplatidae, and Mycetophilidae is presently unclear. It is also possible that a moniliform antenna evolved three times independently in Bibionomorpha. A club-shaped antenna evolved independently in Nymphomyiidae and within Brachycera. This is clearly autapomorphic in the case of Nymphomyiidae, but the interpretation in Brachycera is ambiguous. Club-shaped antennae occur in Drosophilidae,
Syrphidae, Tabanidae, and Stratiomyiidae [59, 97, 98], linked with the presence of an arista in Cyclorrhapha [8]. The club-shaped condition is due to the enlargement of the first flagellomere in Nymphomyiidae and in the brachyceran Drosophilidae, Tabanidae, and Bombyliidae (where the antenna is filiform, but also shortened; [60]). A characteristic apomorphic condition occurring in Brachycera is the reduction of antennal segments (see above). The presence of a Johnston's organ in Culicomorpha and Drosophila [111] is arguably due to reversal. It is conceivable that it also occurs in other groups, but the currently available data are too fragmentary for a reliable interpretation.

Adults of several groups of lower Diptera are short-lived (e.g., Deuterophlebiidae, Nymphomyiidae, and Cecidomyiidae) and 
have to find their mating partner in a short time span. Therefore, the antenna is well developed and bears numerous olfactory sensilla (see [30]). Interestingly, the antennae of adult Brachycera are greatly shortened, compared to the presumptive dipteran groundplan, but apparently still equipped with a highly efficient set of sensilla (e.g., Drosophila; [116]). It was shown in recent studies that the olfactory system performs well and that the short antennae play an important role in finding food sources and suitable oviposition sites [e.g., 117-119].

The shift of the origin of the extrinsic antennal muscles from the tentorium to the head capsule is very likely correlated with the more or less far-reaching reduction of the tentorium, but a phylogenetic pattern is not recognizable. In the groundplan of the order Mm. tentorioscapalis anterior, posterior and medialis (Mm. 1/2/4) still originate on the tentorium. All muscles originate on the head capsule in Tipulidae and in Nymphomyiidae, as in both cases the tentorium is lacking $[50,58]$. In groups with a short vestige of the dorsal arm all or at least two antennal muscles have a tentorial origin (e.g., Trichoceridae, Tanyderidae, Chaoboridae, Syrphidae, and Bombyliidae [58-60]). In Psychodidae, M. tentorioscapalis anterior (M. 1) is bipartite, and one subcomponent originates on the tentorium, whereas the second originates on the head capsule. The muscle is also subdivided in Deuterophlebiidae [28], but this is obviously a result of parallel evolution.

Mandibles. Mandibles are present in the groundplan of Diptera like in Mecoptera and other holometabolan groups [e.g., 8, 80, 81, 115, 120]. However, they are never robust structures functioning as biting devices, but more or less narrow stylet-like structures if present at all. In most groups, they are completely missing (e.g., Tipulomorpha, Deuterophlebiidae, Nymphomyiidae, Bibionomorpha, and Psychodomorpha [28, $30,31,50,58])$. The reduction is apparently correlated with the feeding habits. In most blood-sucking dipterans, mandibles are present and usually elongated and transformed into piercing stylets (e.g., Culicidae, Ceratopogonidae, and Tabanidae $[59,98,99,100,113])$. In Culicidae, they are elongated in females as they only need a blood meal for egg development. They are much shorter in the males which feed on plant sap [108]. In Tabanidae, mandibles are only present in the blood-sucking females, whereas they are absent in the flower-visiting males [98]. Similarly, in Blephariceridae, they are present in the predaceous females but missing in males [121].

Maxilla. The stipites are internalized in Culicidae (cryptostipes of [41]) and also in some groups of Tipuloidea, in Simuliidae, and in Brachycera [e.g., 58-60, 70, 95, 97, 99, 100]. An apomorphic feature of Tipuloidea is the partial fusion of the stipites, and the complete fusion is an apomorphy of Tipulidae [58] (see above). The stipites are also completely fused in Blephariceridae and in some brachyceran groups $[58,70]$, apparently a result of parallel evolution.
According to Hennig [8], cardo and stipes are delimited from each other in the groundplan of Diptera and Brachycera. However, a recognizable border is absent in most dipteran species examined [e.g., 28, 30, 31, 41, 58-60, 70, 94, 95, 99, 100] and also missing in Siphonaptera [83], Nannochoristidae [80], and Boreidae [81]. It was assumed by earlier authors that the cardines are reduced [e.g., 122]. However, the condition of the musculature suggests that the sclerite in question is a product of fusion [e.g., 59, 108, 123, 124]. Among the dipterans examined, cardo and stipes are only separated in Trichoceridae, Dixidae, and Tabanidae [58, 98]. It is not entirely clear whether this separation is a secondary condition or ancestral for Diptera, implying that cardo and stipes fused several times independently within the group.

In the groundplan of the order and in most dipteran taxa, only a single maxillary endite lobe is present [e.g., 58-60, 70, $94,98,100,125]$. This was referred to as galea in older contributions $[41,94,126]$, but its homology with the lacinia has been established in more recent studies [e.g., 59, 93, 95, 108, $122,123]$. Hoyt [70] interpreted the structure as a product of fusion of both elements. However, this interpretation appears questionable as M. craniolacinialis (M. 19) is preserved in some dipteran lineages (e.g., Culicidae, Simuliidae, and Bombyliidae; [59, 60, 95]) as in Mecoptera (Nannochorista, Caurinus, Bittacus, and Merope; [80, 82]), whereas a muscle of the galea is consistently absent. The complete reduction of the maxillary endite lobes is an apomorphic feature occurring in Tipulidae, Limoniidae, Cecidomyiidae, some Mycetophilidae, Axymyiidae, and Anthomyiidae (see [30, 31, 70]). It is apparent that this condition evolved several times independently.

The maxillary palp is five-segmented in the dipteran groundplan, and this condition was found in most species examined. Four-segmented palps evolved in Psychodidae, Mycetophilidae, and Siphonaptera [83, 127]. Palp segments are also reduced in some members of Culicidae [69] and generally in Brachycera (see above). The last palp segment is distinctly elongated in several groups of lower Diptera (and slightly in Syrphidae; [59]) without a recognizable phylogenetic pattern. A sensorial field on the third maxillary palp segment is present in most species of lower Diptera and in Nannochoristidae [80], but the specific condition varies distinctly between the taxa (Figure 4). An apomorphic condition that evolved in Tipulomorpha is the exposed position of the sensilla of the sensorial field, and as a secondarily modified version of Tipulidae, the sensilla are placed in individual, separated grooves [58]. A sensorium with a single groove belongs to the groundplan of Diptera and is also present in Nannochoristidae. A derived condition similar to that found in Tipulidae has evolved in Anisopodidae and in Corethrellidae (Figure 4A).

The origin of M. tentoriostipitalis (M.18) is shifted to the head capsule in Tanyderidae and in Limoniidae, and apparently 
also, in Drosophilidae $[58,97]$, even though the homology of the muscle is not entirely clear in this case.

M. palpopalpalis externus (M. 22) is present in the dipteran groundplan, but absent in the groundplan of Brachycera. The muscle is also missing in Thaumaleidae, Axymyiidae, Scatopsidae, and Aedes, whereas it is present in Culex [99].

Labium. The dorsal surface of the anterior labium forms a distinct concavity in the groundplan of Diptera, a condition also found in Nannochoristidae and in Siphonaptera [80]. In Culicidae, it forms a groove for the piercing mouthparts in their resting position [59, 99, 100, 107, 109], and a similar condition is found in Simuliidae [95, 128], Tabanidae [98], and Siphonaptera [83]. The concavity is reduced in Bibionomorpha excluding Anisopodidae and Scatopsidae. It is also absent in Tipulidae and Asilidae, but present in the groundplan of Tipulomorpha and Brachycera. The loss apparently occurred three times independently [58].

Hennig [8] considered the postmentum (submentum after Gouin [129]; mentum after Peterson [41], Crampton [126]) as part of the dipteran groundplan. However, it is almost generally absent $[41,58-60,95,97,98]$, with the only exception of Ceratopogonidae [113]. It appears likely that the postmentum is fused with other cephalic elements or completely reduced in the dipteran groundplan (potential autapomorphy), implying that the structure occurring in Ceratopogonidae is not homologous with the postmentum of other insects. A correlation between the reduction of the postmentum and the presence of a postgenal bridge [8] is possible but not supported by specific evidence.

Two-segmented labial palps modified as thickened labellae are an autapomorphy of Diptera [e.g., 30, 31, 58-60, 69, 95, 98-100, 107, 125, 128]. They are present in all dipterans with developed mouthparts. Pseudotracheae are a specialized modification of the labellae. This condition evolved independently in some groups of lower Diptera, such as Ptychopteridae, Tipulidae, and Mycetophilidae (partim), and it is typical for Brachycera. The pseudotracheae of brachycerans are more complex and cover a larger area. In Syrphidae, the labellae consist of two rows of collecting channels on the anterior edge and about 40 on the mesal wall [59]. In Tipula, two rows of collecting channels enclose the functional mouth opening [58]. The brachyceran pseudotracheae consist of inner strengthening rings and a number of secondary channels [e.g., 130-132]. The function is the uptake of liquid food by capillary forces and the distribution of saliva [133]. Simple furrows on the inner wall of the labellae are obviously present in the groundplan of Diptera. Owen [100] considered them as pseudotracheae, but Schiemenz [59] demonstrated that the ultrastructure is distinctly different, which implies that they are precursors or were formed independently. The furrows are absent in Blephariceridae and in Limoniidae and in subgroups of Culicomorpha and of Bibionomorpha. The absence is possibly linked with the feeding habit in these groups, but the available information is insufficient for a reliable interpretation. Glossa and Paraglossa are absent in the groundplan of Diptera, as in all other holometabolan groups with the exception of Hymenoptera [e.g., 58-60, 80-82, 88, 95, 100, 120, 128].

The presence of only one premental retractor muscle is ancestral for Diptera. This condition was found in all examined taxa [e.g., 58-60, 70, 95, 98-100, 109, 113] with the exception of Drosophila [111]. As Drosophila is deeply nested within Brachycera, the second bundle is very likely the result of a subdivision of a primarily undivided retractor. An investigation of more brachyceran representatives is necessary for a reliable evaluation of this character. M. palpopalpalis labii primus (M. 35) is absent in the groundplan of Brachycera.

Pharynx and its musculature. M. clypeopalatalis (M. 43) is distinctly enlarged in the groundplan of Diptera and forms a long series of bundles in most taxa $[28,30,31,58-60,98$, $100,109,111,113]$. A postcerebral pharyngeal pump (Mm. 51/52) is also ancestral for the group. It is strongly developed in all groups examined, with the noteworthy exception of Cyclorrhapha [28, 30, 31, 50, 58, 59, 95, 98-100, 109 , 113]. The well-developed sucking pump of dipteran adults is apparently correlated with the uptake of liquid food. It is also well developed in the blood-sucking fleas [83] and also in Nannochoristidae, which also feed on liquid substrates [80].

Salivary pump. A salivary pump with one well-developed muscle is present in the groundplan of Diptera, and this condition is preserved in almost all groups examined. The single muscle (M. hypopharyngosalivarialis, M. 37) is reduced in Axymyiidae, Deuterophlebiidae, and Limoniidae [28, 58]. Deuterophlebiid adults do not consume food, which makes a salivary pumping apparatus superfluous.

Larval head: Head capsule. The larval head is prognathous and fully exposed in the groundplan, and this condition is present in most groups of lower Diptera [29, 32, 45-48, 63, $66,72-75,129,134,135]$. This applies also to larvae of Siphonaptera and of Nannochoristidae and is therefore likely to be part of the antliophoran groundplan. According to Hennig [8], the prognathous head is a derived groundplan feature of Diptera and correlated with the loss of larval thoracic legs. This interpretation appears implausible as the head is also prognathous in larvae of Nannochorista [136] which possess well-developed legs. A similar combination of prognathism and normally developed legs occurs also in other groups of holometabolan insects such as Coleoptera (Adephaga, Histeroidea, and Staphylinidae partim), Neuropterida, and Trichoptera (Rhyacophilidae [e.g., 88]).

Tipuloidea are characterized by a tendency to retract the larval head capsule into the prothorax. The head is strongly retracted in Limoniidae, Cylindrotomidae, and Tipulidae (see [27]). In the presumably basal Pediciidae, the head is only moderately retracted (see [46]) and this probably represents 
a transition state between the fully exposed head in the dipteran groundplan and the completely retracted one in Tipuloidea excl. Pediciidae. The head is also moderately retracted into the prothorax and not fixed in this position in larvae of Axymyiidae and Stratiomyiidae [46], apparently as a result of parallel evolution. A partly reduced head capsule is usually found in dipteran larvae living in soft substrate, whereas it is well developed in larvae exposed in their environment, such as in Culicomorpha or in Bibionidae. However, the immature stages of Tipuloidea occupy a wide range of different habitats [3]. The investigated larvae live mostly in semiaquatic or aquatic environments (Limonia, Tipula, many species of Pediciidae) or alternatively in moss (Cylindrotomidae). In Brachycera, the tendency to retract and to reduce the head capsule is apparent. In Cyclorrhapha, the larval head is always strongly retracted and the head capsule completely reduced $[33,137,138]$.

A larval apomorphy of Tipulomorpha is the ventromedian incision of the head capsule. This condition is only found in members of Tipuloidea and Trichoceridae. A triangular median sinus on the ventral side of the head occurs in Simuliidae [46], but this is clearly a different condition and unique to simuliid larvae. A further autapomorphy of tipuloid larvae is the separation of the dorsomedian fragment from the remaining head capsule by paired dorsolateral incisions. This is related with the general trend to reduce the sclerotized cephalic elements in Tipuloidea. Another derived character of this group is the presence of growth lines on the externolateral plates, as it has also evolved in Deuterophlebiidae, Blephariceridae, and Tanyderidae. In Tanyderidae, a premaxillary suture is present and a possible apomorphy of the group [32]. The suture has also evolved in subgroups of Tipuloidea (Tipulidae, Cylindrotomidae, and Limoniinae: [27, 46, 62]).

A long coronal suture is present in the larval groundplan of Diptera, although it is missing or shortened in most groups. The frontoclypeal transverse ridge is missing in all larvae examined, with the exception of Axymyiidae. Based on the absence of the suture in all other dipteran groups and also in Nannochorista [136] and in Siphonaptera [139], it is plausible to assume that the presence is a secondary feature. The clypeus is subdivided in larvae of Axymyiidae. The same condition is only found in larvae of Limoniidae and Mecoptera [136, 141]. As Axymyiidae is nested within Bibionomorpha and Limoniidae in Tipulomorpha, it is most likely autapomorphic for both groups. The presence of a frontoclypeal suture and the divided clypeus in larvae of Axymyiidae possibly increases the flexibility of the anterior head region. The frons is primarily V-shaped in dipteran larvae [16], but a Ushaped frons has evolved in Chaoboridae and independently in Ceratopogonidae [135].

Larvae of Chaoboridae have well-developed adult compound eyes [142]. Compound eyes also occur in larvae of Panorpa
[141], but in this case, they are true larval structures [143], which evolved secondarily [88].

A hypostomal plate (hypostomium) fused with elements of the head capsule is a groundplan feature of the order and common in lower Diptera. A partly divided hypostomium is present in larvae of Dixidae. A similar condition evolved independently in Tipulidae and in Limoniidae [27]. In Pediciidae, it is completely divided [46] which is a potential autapomorphy of the family. It is separated from the head capsule by a distinct suture in Ptychopteridae, Bibionidae, and Tanyderidae [32, 46, 72, 75], likely an apomorphic condition which evolved independently in these three families. As discussed by Solinas [144], the condition of the hypostomal plate depends mainly on the diet of the larvae in Mycetophilidae. He assumed that it is strongly developed in species feeding on soft gall issues, moderately in larvae feeding on fibrous plant tissue, and poorly in species lacking sap from the gall walls [144]. In the groundplan of Brachycera, a hypostomal bridge is missing, which is arguably correlated with the retraction of the head (see above and [8]). However, this is not the case or only to a lesser degree in tipuloid larvae [27]. The hypostomium is equipped with triangular teeth in the groundplan, arguably an autapomorphy of the order. Ancestral dipteran larvae probably lived in a moist or a wet environment (e.g., Deuterophlebiidae, Nymphomyiidae, and Tipuloidea $[48,145,146])$ where they feed on algae, decaying plant material, or moss. The toothed hypostoma probably helps to remove algae or microorganic material from rocks or other surfaces.

Tentorium. A tentorium with anterior, posterior, and dorsal arms and a tentorial bridge is present in the groundplan. However, dorsal arms and the bridge are missing in most groups and in the groundplan of Brachycera, as it is also the case in adults (see above).

The tentorium is complete reduced in the larvae of Mycetophilidae. Their head forms a "cutterhead" [147], and they live in and feed on fungus [148]. The same occurs in larvae of Axymyiidae, which live in chambers they produce in wood saturated with water. Their diet is probably also soft material, and the tentorium is also reduced [149]. A tendency to reduce the larval tentorium is also present in Bibionomorpha, as the anterior arms are missing in most groups (Bibionomorpha excl. Anisopodidae, and Scatopsidae). As in the adults, reductions of tentorial elements are common. Anterior arms are also missing in Simuliidae, Tipulidae, Pediciidae, and Nymphomyiidae [27, 29, 46].

Labrum. The labrum is partly fused with the head capsule in larvae of Axymyiidae, and also in Bibionidae and in Mycetophilidae. This condition could be a transition state between the free labrum of Anisopodidae and the completely fused one in Cecidomyiidae. The labrum is also fused with the head capsule in several other dipteran groups, but without a recognizable phylogenetic pattern. A subdivided labrum is a 
characteristic feature of Tipulidae and an autapomorphy of the family.

A broad larval labrum is probably a dipteran groundplan feature. A conical labrum is ancestral for brachyceran larvae. However, the same condition has evolved in several lower dipteran families such as Nymphomyiidae, Thaumaleidae, Axymyiidae, Anisopodidae, and Psychodidae [29, 45].

A labrum equipped with a dense field of hairs is a groundplan apomorphy of Diptera (Figure 6B). However, the specific condition in different groups varies strongly, and in some families, a specific arrangement of the labral brush is missing. It is likely used to remove or sweep algae or other small food particles from surfaces. An unusual feature occurring in basal dipteran lineages is the formation of movable premandibles or messores. These structures, which do not occur in other holometabolan groups, form a conspicuous and efficient collecting apparatus in the aquatic larvae of Simuliidae [150, 151].

Strongly developed labral teeth are present in larvae of Anisopodidae. This apomorphic character has independently evolved in Cylindrotomidae [152], as this structural modification is absent in Trichocera and other members of Tipuloidea $[27,45,46,153]$, and consequently in the groundplan of Tipulomorpha.

M. frontoepipharyngalis (M. 9) is absent in larvae of Bibionidae. It is also missing in Cecidomyiidae and in some brachycerans (Therevidae and Stratiomyiidae; [46, 47]) but is present in the groundplan of the order and in most dipteran larvae examined [e.g., 27, 29, 32, 46, 48, 66, 72-74, 135, 154, 155]. The loss obviously occurred several times independently within Bibionomorpha and Brachycera.

Antenna. The larval antennae consist of a basal antennomere and several distinctly developed segments in the groundplan. However, it is one-segmented in most groups and in the groundplan of Brachycera. The presence of only one extrinsic muscle is ancestral, and this condition is found in most groups of lower Diptera. One muscle is also present in Nannochoristidae and in Panorpidae, but two in Boreidae $[136,156]$. The loss of the extrinsic antennal muscles occurred several times in Diptera. A phylogenetic pattern is not recognizable.

The antennae are vestigial in Axymyiidae, Bibionidae, and Mycetophilidae but present in larvae of Cecidomyiidae [46, $47,75]$. The antenna is distinctly developed in the groundplan of Bibionomorpha, but the group shows a clear tendency toward reduction.

In Chaoboridae, Corethrellidae, and Ceratopogonidae [135], the antennal insertion is shifted toward the midline (Figure 6), whereas a lateral insertion belongs to the dipteran groundplan [e.g., 27, 29, 32, 45, 46-48, 65, 72, 75]. The antenna insert on the anterior margin of the head capsule in Chaoborus, in front of the compound eyes (Figure 6A). Larvae of Chaoborus capture copepods and water fleas with this unusual apparatus [157]. The raptorial antennae are an autapomorphy of Chaoboridae. In Corethrellidae, the antenna is simple and bears two horns on the apex (Figure 6B), and the same condition is found in Anopheles [154]. A bifurcate antenna is also present in larvae of Deuterophlebiidae (Figure $3 \mathrm{~A}$ ), but this is likely due to parallel evolution considering the basal position of Deuterophlebiidae.

Mandible. Well-developed, undivided, and relatively stout mandibles moving in a horizontal plane are probably part of the larval groundplan of Diptera. A major evolutionary trend in Diptera is the shift of the axis of movement from vertical to oblique to horizontal [e.g., 27, 62]. The mandibles of several groups of lower Diptera move in a vertical plane, and this applies generally to the hook-shaped mandibles or mouthhooks in Brachycera. It is conceivable that this is linked with the lack of thoracic legs. The more or less hook-shaped mandibles are moved as accessory locomotor organs in several groups of Diptera.

The mandible is sickle-shaped and elongated in Pediciidae [46], apparently an autapomorphy of the family. In Tipulidae, the secondary mandibular joint is shifted posterior to the antennal foramen $[27,46,61,158]$, a unique feature and very likely an autapomorphy of this family. A movable lacinia mobilis is probably a synapomorphy of Tipulidae and of Cylindrotomidae, but it also occurs in Chaoboridae and in Nannochoristidae [62, 136], obviously as a result of parallel evolution. In Chaoboridae, a small intrinsic extensor muscle is present. That this muscle was not found in any other group of dipteran suggests that this is an autapomophic feature which is possibly linked with the predaceous life style.

An anteriorly directed cone on the mesal edge of the mandible is a unique feature of Anisopodidae and an autapomorphy of this family [45]. The mandible is subdivided in larvae of this family as it is also the case in Ptychopteridae and in Brachycera [45, 46, 72]. In Ptychopteridae, the mandible is divided by a furrow, whereas the distal and the proximal parts are separated by a weakly sclerotized zone in Anisopodidae and in Brachycera. It cannot be fully excluded that the subdivided mandible is a synapomorphy of Brachycera and of Bibionomorpha. But this interpretation would imply that an undivided mandible evolved secondarily in Bibionomorpha excluding Anisopodidae.

A multitoothed comb is present on the apical part of the mandible in larvae of Thaumaleidae. This is also the case in larvae of Deuterophlebiidae, Nymphomyiidae, and some Blephariceridae $[16,29,48]$. This is probably linked with the feeding habits of the larvae. All of them live in cold streams and scrape diatoms, microscopic plant material, and algae from rocks [159-161].

M. tentoriomandibularis (M. 13) is missing in all dipteran larvae examined, and also in Siphonaptera and in Mecoptera excl. Nannochoristidae [136]. It is conceivable that the delicate muscle was overlooked in some cases.

Maxilla. A more or less complete and free larval maxilla belongs to the groundplan of Diptera. A cardo completely 
fused with the head capsule (or reduced) has evolved independently in Axymyiidae, Nymphomyiidae, Psychodidae, and some members of Culicomorpha, but it is present as a clearly defined sclerite in the groundplan of the order. In Axymyiidae, it is apparently preserved, even though indistinguishably fused with the stipes. M. tentoriocardinalis (M. 17) is distinctly developed in the larvae of this group.

Different degrees of fusion of the maxillary endite lobes occur in lower dipteran larvae. They are partly fused in Axymyiidae but still recognizable as separate structures, whereas the fusion is complete in Bibionidae and in Cecidomyiidae [46, $47,75]$. The homology of the maxillary elements is still not entirely clear in larvae of some groups, such as in Mycetophilidae, Corethrellidae, and Thaumaleidae.

A dipteran groundplan feature preserved in Deuterophlebiidae is the presence of two-segmented maxillary palps [48]. This condition is also maintained in few other groups of lower Diptera (Bibionidae, Chironomidae, and Axymyiidae; [46, 75, 162]) and also in Therevidae (Brachycera) [46]. The reduction of one palpomere has taken place several times independently and it is one-segmented in most groups.

The absence of M. craniocardinalis (M. 15) is probably ancestral for Diptera, even though one extrinsic maxillary muscle with a cranial origin is present in Exechia and even two in Androprosopa. The homology of these muscles is presently unclear, mainly due to the unclear homology of the corresponding maxillary elements. M. craniocardinalis is also missing in larvae of other groups of Mecopterida [163], and this is possibly an autapomorphy of this lineage [88]. An extrinsic maxillary muscle occurring in Siphonaptera is probably not homologous with M. craniocardinalis [136]. Intrinsic maxillary muscles (Mm. 20/21) are also missing in the groundplan of Diptera.

The presence of $M$. tentoriostipitalis (M. 18) is arguably ancestral in Diptera as it is preserved in larvae of Nymphomyiidae. However, it originates on the head capsule due to the loss of the tentorium, and it cannot be fully excluded, that it is in fact M. craniolacinialis (M. 19). The maxillary endites are not recognizable as separate structures in larvae of Nymphomyiidae. They are likely fused with the stipites (see [29]).

Labium. The labium is distinctly simplified in all groups of Diptera. A separate submentum (as a part of the postmentum) is present in the dipteran groundplan and also in the groundplan of Brachycera. The ancestral condition occurs in Olbiogaster (Anisopodidae) [164] and Psychodidae [16], but the basal labial element is absent in most groups of lower Diptera [e.g., 27, 29, 45, 46, 73, 74].

Labial palps are greatly reduced and appear one-segmented in the groundplan. They are present in Anisopodidae, Blephariceridae, and Tabanidae [45, 46, 63]. Even though they are completely reduced in almost all groups of lower Diptera, they are preserved in the groundplan of Brachycera according to Hennig [8] (Tabanidae; [46]) and also in the groundplan of Cyclorrhapha [165, 166].

Only one extrinsic labial muscle occurs in dipteran larvae, as it is also the case in adults. M. praementopalpalis (M. 34) is probably absent in the groundplan.

Pharynx. A pharyngeal filter is present in a number of lower dipteran families. It is absent in Mecoptera and in Siphonaptera [136, 139, 141], and also in Deuterophlebiidae and in Nymphomyiidae, and is therefore probably not a part of the dipteran groundplan. Its presence is arguably a groundplan apomorphy of Diptera, excluding Deuterophlebiidae and Nymphomyiidae, with parallel secondary loss in different groups such as Tipuloidea, Bibionomorpha (partim), Simuliidae, Thaumaleidae, and the entire Brachycera [16, 27, $46,47,73,75,135,155]$. The homology of the filter in different groups is also not entirely clear. It differs considerably among the lower dipteran groups. It is highly specialized and complex in Axymyiidae, whereas it consists only of simple combs in Anopheles (see [154], fig. 14).

M. tentoriohypopharyngalis (M. 42) is probably absent in the groundplan. The homology of a tentoriohypopharyngeal muscle described for Trichocera $[167,168]$ is questionable. The character polarity of the presence or the absence of this muscle is also unclear. Hinton [163] interpreted the loss as a possible synapomorphy of Diptera, Siphonaptera, and Pistillifera. This interpretation is not convincing according to Beutel et al. [136], who postulated the presence in Nannochorista and in Panorpa [141], considering a 'Musculus palpi labialis' as likely homologue of M. tentoriohypopharyngalis (M. 42).

M. tentoriobuccalis anterior (M. 48) and the muscles forming the postcerebral pharyngeal pump (Mm. 50-52) are completely missing in brachyceran larvae. The absence of M. tentoriobuccalis anterior is a common feature in Diptera, but as it occurs in several families and also in Mecoptera [136, 141] and Siphonaptera [139]. This condition is apparently ancestral for the order. The same applies to the muscles of the postcerebral pharyngeal pump.

\section{CONCLUSION}

Adults of Diptera are usually short lived, with a life span hardly extending beyond copulating and laying eggs. Feeding is not necessary in many cases, and the mouthparts are largely or completely reduced in different groups. Adults of most groups are quite similar in their life habits, and the head is characterized by similar reductions in many groups. One character complex which shows already far-reaching modifications in the groundplan is the food uptake apparatus. The paired mouthparts are strongly modified with a distinct tendency toward reduction, and the labium is transformed into a device for the uptake of liquid food. Strongly developed cibarial and postcerebral pumping apparatuses, which belong to the groundplan of the order, are also relevant in this functional context. The optimization of the uptake of more or less liquefied substrates is one major evolutionary trend in 
Diptera, with several cases of parallel evolution. Mandibles are already strongly modified in the groundplan and completely reduced with their muscles in most lineages, a loss which obviously occurred several times independently. The mandibles are usually preserved in blood-sucking species, especially in females which need a blood meal for producing fertile eggs. They are preserved in very few groups of Brachycera (e.g., Tabanidae and Dolichopodidae [98, 169]) but are absent in the groundplan of Cyclorrhapha [8]. The maxillae, which are already strongly modified in the groundplan, are further simplified within the group. They play a minor role in the food uptake if at all. Transformations of the labium play a major role. The labellae are one of the conspicuous autapomorphies of the order. Pseudotracheae evolved several times within the group. These specialized surface structures create capillary forces and thus facilitate the uptake of liquid food.

Conspicuous transformations of the antennae take place within the group, with largely unmodified filiform antennae in the groundplan (e.g., Culicidae), moniliform antennae in some lower dipteran families (e.g., Bibionidae), and strongly shortened and transformed antennae (7 or less antennomeres) in Brachycera, with a characteristic whip-like arista as a common feature in Cyclorrhapha. The functional interpretation is difficult in this case. The antennae and their sensilla play an important role in the identification of suitable food substrates and oviposition sites [e.g., 117-119].

A characteristic feature found in many groups is the very large size of the compound eyes. This is probably related with the excellent flying abilities and probably also with the necessity to find a mating partner within a relatively short time span, as it is also the case in the short-lived strepsipterans [e.g., 170]. As adult dipterans take up liquid food and strong mechanical forces are not created during this process, they do not need a strong reinforcement of the head capsule. This was likely a precondition for the formation of very large compound eyes, which results in extensive zones of mechanical weakness.

Another characteristic likely related with the excellent flight performance is the cuticular surface covered with a dense vestiture of microtrichiae on all body parts. As in strepsipterans [e.g., 170], this specific surface sculpture improves the flight performance. Another possible function could be water repellence.

Dipteran larvae live mostly in wet environment and are frequently aquatic. Most of them, especially brachyceran larvae, live in the substrate they feed on. In aquatic and free living larvae, the head is fully exposed, whereas larvae living in their substrate show a tendency to retract it into the anterior thorax. This process is accompanied by a more or less farreaching reduction of the sclerotized parts of the head capsule. The movability of the larvae is strongly constrained as thoracic legs are completely missing in all groups. The mouthparts of several larvae are involved in the locomotion, especially in brachyceran groups, and the oblique or vertical plane of movement of the mandibles (mouth hooks in Cyclorrhapha) can be seen in this context. The feeding habits and mouthparts of dipteran larvae are much more diverse than in the adults. The larvae can be grazers, filter feeders, predators, or simply feed on the substrate they live in. They evolved specific adaptations to their feeding habit, such as a toothed hypostoma, mandibular combs, a pharyngeal filter apparatus, or a more or less extensive labral fan.

Larval antennae play a very minor role compared to those of the adults. They are greatly or completely reduced in many groups. This is possibly related to the habit of females to deposit the eggs at oviposition sites where suitable food for the larvae is readily available.

\section{ACKNOWLEDGMENTS}

We are grateful to the following collagues for providing valuable material: Eric Anton (Jena), Hans Pohl (FSU Jena), Greg Courtney (Iowa State University), Peter Zwick (Limnologische Fluss-Station Schlitz), Marion Harris (North Dakota State University), Erik Blosser (University of Florida), Pjotr Oosterbroek (Amsterdam), Markus Knaden (Max-PlanckInstitute for Chemical Ecology, Jena), Andrew Parker (International Atomic Energy Agency, Vienna), Frank Hünefeld (Jena), Frank Friedrich (Universität Hamburg) and Richard Leschen (New Zealand Arthropod Collection). We thank Janin Naumann for preparing histological section series of excellent quality. The study was funded by the Deutsche Forschungsgemeinschaft (BE 1789/6-1).

\section{REFERENCES}

[1] Pape T, Blagoderov V, Mostovski MB. Order Diptera Linnaeus 1758. In: Zhang z-Q, editor. Animal biodiversity: an outline of higher-level classification and survey of taxonomic richness. Zootaxa. 2011;3148:222-29.

[2] Krzemiński W, Krzemińska E. Triassic Diptera: description, revisions and phylogenetic relations. Acta Zool Cracoviensia. 2003;46(suppl. Fossil Insects):153-84. doi:10.11646/zootaxa. 3710.1 .6

[3] Alexander CP, Byers GW. Tipulidae. In: McAlpine JF, Peterson BV, Shewell GE, Teskey HJ, Vockeroth JR, Wood, DM, editors. Manual of Nearctic Diptera. Vol. 1. Research Branch, Agriculture Canada, Canadian Government Publishing Centre, Hull, Quebec, Canada, Monograph 1981;27:153-190.

[4] Anton E, Niederegger S, Beutel RG. Beetles and flies collected on pig carrion in an experimental setting in Thuringia and their forensic implications. Med Vet Entomol. 2011;25(4):35364. doi:10.1111/j.1365-2915.2011.00975.x

[5] Grimaldi D, Engel MS. Antliophora: scorpionsflies, fleas and true flies. In: Grimaldi D, Engel MS, editors. Evolution of the insects. New York: Cambridge University Press; 2005: 468-47.

[6] Schneeberg K, Beutel RG. 6.35. Diptera. In: Beutel RG, Friedrich F, Ge S-Q, Yang X-K, editors. Insect morphology and phylogeny. Berlin: De Gruyter; 2013:467-482.

[7] Hennig W. Kritische Bemerkungen zum phylogenetischen System der Insekten. Beitr. Entomol. 1953;3:1-85.

[8] Hennig W. Diptera (Zweiflügler). In: Helmcke J-G, Starck D, Wermuth $\mathrm{H}$, editors. Handbuch der Zoologie. IV. Band: 
Arthropoda, 2. Hälfte: Insecta. 2 Edition. Berlin, New York: Walter de Gruyter; 1973:1-337.

[9] Wood DM, Borkent A. Phylogeny and classification of the Nematocera. In: McAlpine JF, Peterson BV, Shewell GE, Teskey HJ, Vockeroth JR, Wood, DM, editors. Manual of Nearctic Diptera. Research Branch, Agriculture Canada, Canadian Government Publishing Centre, Hull, Quebec, Canada; 1989: 1371-1395.

[10] Sinclair BJ. A phylogenetic interpretation of the Brachycera (Diptera) based on the larval mandible and associated mouthpart structures. Syst Entomol. 1992;17(3):233-52. doi:10.1111/j.1365-3113.1992.tb00335.x

[11] Michelsen V. Neodiptera: new insights into the adult morphology and higher level phylogeny of Diptera (Insecta). Zool J Linn Soc. 1996b;117(1):71-102. doi:10.1111/j.1096-3642. 1996.tb02149.x

[12] Beutel RG, Gorb SN. Ultrastructure of attachment specialization of hexapods (Arthropoda): evolutionary patterns inferred from a revised ordinal phylogeny. J Zool Syst Evol Res. 2001;39(4):177-207. doi:10.1046/j.1439-0469.2001.00155.x

[13] Shcherbakov DE, Lukashevich ED, Blagoderov VA. Triassic Diptera and initial radiation of the order. Int J Dipterol Res. 1995; 6: 75-115.

[14] Blagoderov V, Grimaldi DA, Fraser NC. How time flies for flies: Diverse Diptera from the triassic of Virginia and the early radiation of the order. Am Mus Novit. 2007;3572:1-39. doi:10.1206/0003-0082(2007)509[1:HTFFF]2.0.C0;2

[15] Stary J. The wing stalk in Diptera, with some notes on the higher-level phylogeny of the order. Eur J Entomol. 2008;105 (1):27-33. doi:10.14411/eje.2008.003

[16] Oosterbroek P, Courtney G. Phylogeny of the nematocerous families of Diptera (Insecta). Zool J Linn Soc. 1995;115 (3):267-311. doi:10.1111/j.1096-3642.1995.tb02462.x

[17] Yeates DK, Wiegmann BM. Congruence and controversity: toward higher-level phylogeny of Diptera. Ann Rev Entomol. 1999;44(1):397-428. doi:10.1146/annurev.ento.44.1.397

[18] Yeates DK, Wiegmann BM. The evolutionary biology of flies. New York, NY: Columbia University Press; 2005.

[19] Yeates DK, Wiegmann BM, Courtney GW, Meier R, Lambkin C, Pape T. Phylogeny and systematics of Diptera: two decades of progress and prospects. Zootaxa. 2007;1668:565-90.

[20] Bertone MA, Courtney GW, Wiegmann BM. Phylogenetics and temporal diversification of the earliest true flies (Insecta: Diptera) based on multiple nuclear genes. Syst Entomol. 2008;33(4):668-87. doi:10.1111/j.1365-3113.2008.00437.x

[21] Lambkin CL, Sinclair BJ, Pape T, Courtney GW, Skevington JH, Meier R, Yeates DK, Blagoderov V, Wiegmann BM. The phylogenetic relationship among infraorders and subfamilies of Diptera based on morphological evidence. Syst Entomol. 2013;38(1):164-179. doi:10.1111/j.1365-3113.2012.00652.x

[22] Lindner E. 3. Paläontologie und Abstammung; 4. Das System der Dipteren. In: Lindner E, editor. Die Fliegen der paläarktischen Region, Band 1. Stuttgart: E. Schweizerbart'sche Verlagsbuchhandlung; 1949:77-104.

[23] Wiegmann BM, Trautwein MD, Winkler IS, Barr NB, Kim J-W, Lambkin C, Bertone MA, Cassel BK, Bayless KM, Heimberg AM, Wheeler BM, Peterson KJ, Pape T, Sinclair BJ, Skevington JH, Blagoderov V, Caravas J, Narayanan Kutty S, Schmidt-Ott U, Kampmeier GE, Thompson FC, Grimaldi DA, Beckenbach AT, Courtney GW, Friedrich M, Meier R, Yeates DK. Episodic radiations in the fly tree of life. PNAS. 2011;108(14):5690-95. doi:10.1073/pnas.1012675108

[24] Hackmann W, Vaisänen R. Different classification systems of Diptera. Ann Zool Fenn. 1982;19:209-19.
[25] Woodley NE. Phylogeny and classification of the "orthorraphous" Brachycera. In: McAlpine JF, Peterson BV, Shewell GE, Teskey HJ, Vockeroth JR, Wood, DM, editors. Manual of Nearctic Diptera. Research Branch, Agriculture Canada, Canadian Government Publishing Centre, Hull, Quebec, Canada; 1989:1333-1370.

[26] Friedrich M, Tautz D. Evolution and phylogeny of the Diptera: a molecular phylogenetic analysis using $28 \mathrm{~S}$ rDNA sequences. Syst Biol. 1997;46(4):674-98. doi:10.1093/sysbio/46.4.674

[27] Neugart C, Schneeberg K, Beutel RG. The morphology of the larval head of Tipulidae (Diptera, Insecta) - the dipteran groundplan and evolutionary trends. Zool Anz. 2009;248 (3):213-35. doi:10.1016/j.jcz.2009.10.001

[28] Schneeberg K, Courtney GW, Beutel RG. Adult head structures of Deuterophlebiidae (Insecta), a highly derived "ancestral" dipteran lineage. Arthropod Struct Dev. 2011;40(1):93-104. doi:10.1016/j.asd.2010.07.002

[29] Schneeberg K, Friedrich F, Courtney GW, Wipfler B, Beutel RG. The larvae of Nymphomyiidae (Diptera, Insecta) - ancestral and highly derived? Arthropod Struct Dev. 2012;41:293-301. doi:10.1016/j.asd.2012.01.002

[30] Schneeberg K, Polilov A, Harris MO, Beutel RG. The adult head morphology of the Hessian fly Mayetiola destructor (Diptera, Cecidomyiidae). J Morphol. 2013a;274(11):1299-1311. doi:10.1002/jmor.20180

[31] Schneeberg K, Krause K, Beutel RG. The adult head morphology of Axymyia furcata (Axymyiidae, Diptera). Arthropod Syst Phylogeny. 2013b;72:91-102.

[32] Wipfler B, Courtney GW, Craig DA, Beutel RG. First $\mu$ CT-based 3D-reconstruction of a dipteran larva - the head morphology of Protanyderus (Tanyderidae) and its phylogenetic implications. J Morphol. 2012a;273(9):968-80. doi:10.1002/jmor. 20035

[33] Wipfler B, Schneeberg K, Löffler A, Hünefeld F, Meier R, Beutel RG. The skeletomuscular system of the larva of Drosophila melanogaster (Drosophilidae, Diptera) - a contribution to the morphology of a model organism. Arthropod Struct Dev. 2013;42(1):47-68. doi:10.1016/j.asd.2012.09.005

[34] Friedrich F, Matsumura Y, Pohl H, Bai M, Hörnschemeyer T, Beutel RG. Insect morphology in the age of phylogenomics innovative techniques and its future role in systematics. Entomol Science. 2013b;17: 1-24.

[35] Pohl H. A scanning electron microscopy specimen holder for viewing different angles of a single specimen. Microsc Res Techniq. 2010;73(12):1073-1076. doi:10.1002/jemt.20835

[36] Klaus AV, Kulasekera VL, Schawaroch V. Three-dimensional visualization of insect morphology using confocal laser scanning microscopy. J Microsc. 2003;212(2):107-121. doi:10.1046/j.1365-2818.2003.01235.x

[37] Beckmann F, Donath T, Fischer J, Dose T, Lippmann T, Lottermoser L, Martins RV, Schreyer A. New development for synchrotron-radiation-based microtomography at DESY. Proc SPIE 2006. doi:10.1117/12.680360

[38] Friedrich F, Beutel RG. Micro-computer tomography and a renaissance of insect morphology. Proc SPIE. 2008; 7078:70781U. doi:10.1117/12.794057

[39] Friedrich F, Pohl H, Hünefeld F, Beckmann F, Herzen, J, Beutel RG. SR $\mu$ CT-based study on external and internal structures of adults and larvae of Endopterygota (Hexapoda). Hasylab Annual Review 2007; 2008.

[40] Maddison WP, Maddison DR. Mesquite: A modular system for evolutionary analysis. 2011; Version 2.71 and 2.73.

[41] Peterson A. The head-capsule and mouth-parts of Diptera. Illinois Biol Monogr. 1916;3:1-113. 
[42] Rabosky DL. Extinction rates should not be estimated from molecular phylogenies. Evolution. 2010;64:1816-24. doi:10.1111/j.1558-5646.2009.00926.x

[43] Cutten FEA, Kevan DKMcE. The Nymphomyiidae (Diptera), with special reference to Palaeodipteron walkeri ide and its larva in Quebec, and a description of a new genus and species from India. Can J Zool. 1970;48:1-24. doi:10.1139/z70-001

[44] Courtney GW. Life history patterns of Nearctic mountain midges (Diptera:Deuterophlebiidae). J North American Benthol Society. 1991a;10:177-197. doi:10.2307/1467577

[45] Anthon H. Der Kopfbau der Larven einiger nematoceren Dipterenfamilien: Rhyphidae, Trichoceridae, Psychodidae and Ptychopteridae. Spolia Zoologica Musei Hauniensis. 1943a; 3:1-61.

[46] Cook EF. The evolution of the head in the larvae of the Diptera. Microentomol. 1949;14:1-57.

[47] Solinas M. Morfologia, anatomia e organizzazione funzionale del capo della larva matura de Phaenobremia aphidimyza (Rondani). Entomologica. 1968;4:1-44.

[48] Courtney GW. Cuticular morphology of larval mountain midges (Diptera: Deuterophlebiidae): implications for the phylogenetic relationships of Nematocera. Can J Zool. 1990b;68:556-578. doi:10.1139/z90-081

[49] Courtney GW. Phylogenetic analysis of Blephariceromopha, with special reference to mountain midges (Diptera: Deuterophlebiidae). Syst Entomol. 1991b;16:137-172. doi:10. 1111/j.1365-3113.1991.tb00683.x

[50] Tokunaga M. A morphological study of a nymphomyiid fly. Philippine J Sci. 1935;56:127-214.

[51] Sæther OA. Phylogeny of Culicomorpha (Diptera). Syst Entomol. 2000;25:223-34.

[52] Sinclair BJ, Borkent A, Wood DM. The male genital tract and aedeagal components of the Diptera with discussion of their phylogenetic significance. Zool J Linnean Soc. 2007;150:71142. doi:10.1111/j.1096-3642.2007.00314.x

[53] Hennig W. Insect phylogeny. New York (NY): Academic Press; 1981.

[54] Dahl C. Comparison of postembryonic organization of the genital segments in Trichoceridae, Tipulidae, and Anisopodidae (Diptera, Nematocera). Zool Scripta. 1980;9:165-85. doi:10.1111/j.1463-6409.1980.tb00662.x

[55] Shcherbakov DE, Lukashevich ED, Blagoderov VA. Triassic Diptera and initial radiation of the order. Int J Dipterol Res. 1995;6: 75-115.

[56] Sinclair BJ, Cumming JM, Brooks SE. Male terminalia of Diptera (Insecta): a review of evolutionary trends, homology and phylogenetic implications. Insect Syst Evol. 2013;44:373-415. doi:10.1163/1876312X-04401001

[57] Friedemann K, Schneeberg K, Beutel RG. Fly on the wall attachment structures in lower Diptera. Syst Entomol. 2014:39:460-73.

[58] Schneeberg K, Beutel RG. The adult head structures of Tipulomorpha (Diptera, Insecta) and their phylogenetic implications. Acta Zoologica. 2011;92:316-43. doi:10.1111/j.14636395.2010.00463.x

[59] Schiemenz H. Vergleichende funktionell-anatomische Untersuchungen zur Kopfmuskulatur von Theobaldia und Eristalis (Dipt. Culicid. und Syrphid.). Deutsche Entomol Z. 1957;4:268-331. doi:10.1002/mmnd.19570040503

[60] Szucsich NU, Krenn HW. Morphology and function of the proboscis in Bombyliidae (Diptera, Brachycera) and implications for proboscis evolution in Brachycera. Zoomorph. 2000;120: 79-90. doi:10.1007/s004350000025
[61] Selke K. Biologische und morphologische Studien an schädlichen Wiesenschnaken (Tipulidae, Dipt.). Z wiss Zool. 1936;148:465-555.

[62] Oosterbroek P, Theowald B. Phylogeny of the Tipuloidea based on characters of larvae and pupae (Diptera, Nematocera), with an index to the literature except Tipulidae. Tijdschr Entomol. 1991;134:211-67.

[63] Anthon H, Lyneborg L. The culticuar morphology of the larval head capsule in Bephariceroidae (Diptera). Sp Zool Mus Haun. 1968;27:1-56.

[64] Hennig W. Die Larvenformen der Diptera. 2. Teil. Berlin: Akademie-Verlag; 1968b.

[65] Lindner E. Beiträge zur Kenntnis der Larven der Limoniidae. Z Morph Ökol Tiere. 1959;48:209-319.

[66] Felix M. Recherches sur l'anatomie céphalique d'une larve de Dixa (Paradixa) (Diptére Nématocére). Trav lab Zool Stat Aquic Grimaldi Fac Sci Dijon. 1962;43:1-49.

[67] Hesse AJ. A revision of the Bombyliidae (Diptera) of South Africa. Annals South Afr Mus, Cape Town. 1938;34:1-1053.

[68] Hesse AJ. A revision of the Bombyliidae (Diptera) of South Africa II. Annals South Afr Mus, Cape Town. 1956; 35:1-972.

[69] Harbach RE, Kitching IJ. Phylogeny and classification of the Culicidae (Diptera). Syst Entomol. 1998;23:327-370. doi:10.1046/j.1365-3113.1998.00072.x

[70] Hoyt CP. The evolution of the mouthparts of adult Diptera. Microentomol. 1952;17:38-72.

[71] Anthon H. Larval morphology of Mischoderus (Insecta, Diptera, Nematocera, Tanyderidae) with notes on tanyderid affinities. Zool Scripta. 1988;17:381-97. doi:10.1111/j.14636409.1988.tb00114.x

[72] Kramer S. The musculature of the head of the phantom crane fly larva Bittacomorpha (Diptera, Ptychopteridae). J Morphol. 1954;94:409-37. doi:10.1002/jmor.1050940206

[73] Cook EF. The morphology of the larval heads of certain Culicidae (Diptera). Microentomol. 1944a;9:37-84.

[74] Cook EF. On the morphology of the head of Chironomus. Microentomol. 1944b;9: 69-77.

[75] Perraudin J. Recherches sur l'anatomie céphalique des larves de bibionides et de lycoriides (Dip. Nematocera). Trav Lab Zool Stat Aquic Grimaldi Fac Sci Dijon. 1961;41:1-47 (+Figs).

[76] Denis JR, Bitsch J. Morphologie de la Tète des Insectes. In: Grassé PP, editor. Traité de Zoologie, Tome VIIII insectes, Tête, Aile, Vol. Fascicule I. Paris: Masson et Cie Éditeurs; 1973.

[77] Duda 0. Bibionidae. In: Lindner E, editor. Die Fliegen der palaearktischen Region. Stuttgart; Schweizerbart'sche Verlangsbuchhandlung; 1930:1-205.

[78] Hardy DE. Bibionidae. In: McAlpine JF, Peterson BV, Shewell GE, Teskey HJ, Vockeroth JR, Wood DM, editors. Manual of Nearctic Diptera, Research Branch, Agriculture Canada; 1981: 217-22.

[79] James MT. Stratiomyiidae. In: McAlpine JF, Peterson BV, Shewell GE, Teskey HJ, Vockeroth JR, Wood DM, editors. Manual of Nearctic Diptera, Research Branch, Agriculture Canada; 1981:497-512.

[80] Beutel RG, Baum E. A longstanding entomological problem finally solved? Head morphology of Nannochorista (Mecoptera, Insecta) and possible phylogenetic implications. J Zool Syst Evol Res. 2008;46:346-67. doi:10.1111/j.1439-0469.2008.00473.x

[81] Beutel RG, Friedrich F, Whiting MF. Head morphology of Caurinus (Boreidae, Mecoptera) and its phylogenetic implications. Arthropod Struct Dev. 2008a;37(5):418-33. doi:10.1016/j.asd.2008.02.002 
[82] Friedrich F, Pohl H, Beckmann F, Beutel RG. The head of Merope tuber (Meropidae) and the phylogeny of Mecoptera (Hexapoda). Arthropod Struct Dev. 2013a;42(1):69-88. doi:10.1016/j.asd.2012.09.006

[83] Wenk P. Der Kopf von Ctenocephalus canis (Curt.) (Aphaniptera). Zool Jahrb (Abt Anat Ontogenie Tiere). 1953; 73:103-64.

[84] Beutel RG, Pohl H. Head structures of males of Strepsiptera (Hexapoda) with embasis on basal splitting events within the order. J Morphol. 2006;267(5):536-54. doi:10.1002/jmor. 10261

[85] Swart CC, Felgenhauer BE. Structure and function of the mouthparts and salivary gland complex of the giant waterbug, Belostoma lutarium (Stål) (Hemiptera: Belostomatidae). Ann Entomol Soc Am. 2003;96(6): 870-82. doi:10.1603/00138746(2003)096[0870:SAFOTM]2.0.CO;2

[86] Weirauch C. Voragocoris schuhi, a new genus and species of neotropical Schizopterinae (Hemiptera: Heteroptera: Schizopteridae). Entomol Am. 2012;118(1):285-94. doi:10. 1664/12-RA-036.1

[87] Wheeler WC, Whiting M, Wheeler QD, Carpenter JM. The phylogeny of the extant hexapod orders. Cladistics. 2001;17 (2):113-69. doi:10.1111/j.1096-0031.2001.tb00115.x

[88] Beutel RG, Friedrich F, Hörnschemeyer T, Pohl H, Hünefeld F, Beckmann F, Meier R, Misof B, Whiting MF, Vilhelmsen L. Morphological and molecular evidence converge upon a robust phylogeny of the megadiverse Holometabola. Cladistics 2011;27(4):341-55. doi:10.1111/j.1096-0031.2010.00338.x

[89] Niehuis 0, Hartig G, Grath S, Pohl H, Lehmann J, Tafer H, Donath A, Krauss V, Eisenhardt C, Hertel J, Petersen M, Mayer C, Meusemann K, Peters RS, Stadler PF, Beutel RG, BornbergBauer E, McKenna DD, Misof B. Genomic and morphological evidence converge to resolve the enigma of Strepsiptera. Curr Biol. 2012;22(14):1309-13. doi:10.1016/j.cub.2012 05.018

[90] Peters RS, Meusemann K, Petersen M, Wilbrandt J, Ziesmann J, Donath A, Mayer C, Kjer KM, Aspöck U, Aspöck H, Aberer A, Stamatakis A, Friedrich F, Hünefeld F, Niehuis O, Beutel RG, Misof B. The evolutionary history of holometabolous insects inferred from transcriptome-based phylogeny and comprehensive morphological data. Evolut Biol. 2014;14:52. doi:10.1186/1471-2148-14-52

[91] Misof B, Liu S, Meusemann K, Peters RS, Donath A, Mayer C, Frandsen PB, Ware J, Flouri T, Beutel RG, Niehuis O, Petersen M, Izquierdo-Carrasco F, Wappler T, Rust J, Aberer AJ, Aspöck U, Aspöck H, Bartel D, Blanke A, Berger S, Bohm A, Buckley TR, Calcott B, Chen J, Friedrich F, Fukui M, Fujita M, Greve C, Grobe P, Gu S, Huang Y, Jermiin LS, Kawahara AY, Krogmann L, Kubiak M, Lanfear R, Letsch H, Li Y, Li Z, Li J, Lu H, Machida R, Mashimo Y, Kapli P, Mckenna DD, Meng G, Nakagaki Y, Navarrete-Heredia JL, Ott M, Ou Y, Pass G, Podsiadlowski L, Pohl H, Von Reumont BM, Schutte K, Sekiya K, Shimizu S, Slipinski A, Stamatakis A, Song W, Su X, Szucsich NU, Tan M, Tan X, Tang M, Tang J, Timelthaler G, Tomizuka S, Trautwein $\mathrm{M}$, Tong $\mathrm{X}$, Uchifune $\mathrm{T}$, Walzl MG, Wiegmann BM, Wilbrandt J, Wipfler B, Wong TKF, Wu Q, Wu G, Xie Y, Yang S, Yang $Q$, Yeates DK, Yoshizawa K, Zhang Q, Zhang R, Zhang W, Zhang Y, Zhao J, Zhou C, Zhou L, Ziesmann T, Zou S, Li Y, Xu X, Zhang $\mathrm{Y}$, Yang $\mathrm{H}$, Wang J, Wang J, Kjer KM, Zhou X. Phylogenomics resolves the timing and pattern of insect evolution. Science. 2014;346(6210):763-67. doi:10.1126/science. 1257570

[92] Malloch JR. A preliminary classification of diptera, exclusive of pupipara, based upon larval and pupal characters, with keys to imagines in certain families. Illinois Nat Hist Surv Bull. 1917;12:161-409.

[93] Krenn HW, Plant JD, Szucsich NU. Mouthparts of flower-visiting insects. Arthropod Struct Dev. 2005;34(1):1-40. doi:10.1016/j.asd.2004.10.002

[94] Williams IW. The external morphology of the primitive tanyderid dipteron Protoplasa fitchii O.S., with notes on the other Tanyderidae. N Y Entomol Soc. 1933;41:1-35.

[95] Wenk P. Anatomie des Kopfes von Wilhelmia equina L. (Simuliidae syn. Melusinidae, Diptera). Zool Jahrb (Abt Anat Ontogenie Tiere). 1962;80:81-134.

[96] Oosterbroek P. The European families of the Diptera. Identification, diagnosis, biology. Zeist (the Netherlands): KNNV Publishing; 2006.

[97] Ferris GF. External morphology of the adult. In: Demerec M, editor. Biology of Drosophila. New York (NY): John Wiley \& Sons; $1950: 368-419$.

[98] Bonhag PF. The skeleton-muscular mechanism of the head and abdomen of the adult horsefly (Diptera: Tabanidae). Trans Am Entomol Soc. 1951;77:131-202.

[99] Christophers SR. The imago. In: Aedes aegypti (L.) the yellow fever mosquito. Its life history, bionomics and structure. Cambridge: Cambridge University Press; 1960.

[100] Owen WB. Morphology of the head skeleton and muscles of the mosquito, Culiseta inornata (Williston) (Diptera: Culicidae). J Morphol. 1985;183(1):51-85. doi:10.1002/jmor.1051830105

[101] Snodgrass RE. The head. In: Snodgrass RE, editor. Principles of Insect morphology. Chapter VI. New Delhi (India): CBS Publishing \& Distributors; 1994:100-129.

[102] Beutel RG, Vilhelmsen L. Head anatomy of Xyelidae (Hexapoda: Hymenoptera) and phylogenetic implications. Org Divers Evol. 2007;7(3):207-30. doi:10.1016/j.ode.2006. 06.003

[103] Beutel RG, Zimmermann D, Krauß M, Randolf S, Wipfler B. Head morphology of Osmylus fulvicephalus (Osmylidae, Neuroptera) and its phylogenetic implications. Org Divers Evol. 2010b;10(4):311-29. doi:10.1007/s13127-010-0024-0

[104] Wipfler B, Wieland F, DeCarlo D, Hörnschemeyer T. Cephalic morphology of Hymenopus coronatus (Insecta: Mantodea) and its phylogenetic implications. Arthropod Struct Dev. 2012b; 41(1):87-100. doi:10.1016/j.asd.2011.06.005

[105] Wiegmann BM, Trautwein MD, Kim J, Bertone M, Winterton SL, Cassel BK, Yeates DK. Single-copy nuclear genes resolve the phylogeny of the holometabolous insect orders. BMC Biol. 2009;7(1):34. doi:10.1186/1741-7007-7-34

[106] McAlpine JF. 1981. Morphology and terminology - adults. In: McAlpine JF, Peterson BV, Shewell GE, Teskey HJ, Vockeroth JR, Wood DM, editors. Manual of Nearctic Diptera. Agriculture Canada Monograph 27, Vol. 1: 9-63.

[107] Vogel R. Kritische und ergänzende Mitteilungen zur Anatomie des Stechapparates der Culiciden und Tabaniden. Zool Jahrb (Abt Anat Ontogenie Tiere). 1921;42:259-82.

[108] Snodgrass RE. The anatomical life of the mosquito. Smithson Misc Collect. 1959;139:1-87.

[109] Thompson MT. Alimentary canal of the mosquito. Proc Boston Soc Nat His. 1905;32:145-202 (pl. 12-17).

[110] Reid GDF. Structure and function of the cibarial armature in Simuliidae, 1994. Med Veter Entomol. 2008;8: 295-301.

[111] Miller A. The internal anatomy and histology of the imago of Drosophila melanogaster. In: Demerec M editor. Biology of Drosophila. New York (NY): John Wiley \& Sons, Inc.; 1950: 420-534.

[112] Matsuda R. Morphology and evolution of the Insect head. Mem Am Entomol Inst. 1965;4:1-334. 
[113] Gad AM. The head-capsule and mouth-parts in the Ceratopogonidae. Bull Soc Fouad Entomol. 1951;35:17-75.

[114] v Kéler S. Entomologisches Wörterbuch, mit besonderer Berücksichtigung der morphologischen Terminologie. Berlin (Germany): Akademie-Verlag; 1963.

[115] Heddergott H. Kopf und Vorderdarm von Panorpa communis L. Zool Jahrb (Abt Anat Ontogenie Tiere) 65: 229-94.

[116] Stocker R.F. 1994. The organization of the chemosensory system in Drosophila melanogaster: a rewiew. Cell Tissue Res. 1938;275(1):3-26. doi:10.1007/BF00305372

[117] Hansson BS, Stensmyr MC. Evolution of insect olfaction. Neuron. 2011;72(5):698-711. doi:10.1016/j.neuron.2011. 11.003

[118] Date P, Dweck HKM, Stensmyr MC, Shann J, Hansson BS, Rollmann SM. Divergence in olfactory host plant preference in D. mojavensis in response to cactus host use. PLOS one. 2013;8:e70027.

[119] Dweck HKM, Ebrahim SAM, Kromann S, Bown D, Hillbur Y, Sachse S, Hansson BS, Stensmyr MC. Olfactory preference for egg laying on Citrus substrates in Drosophila. Curr Biol. 2013;23(24): 2472-2480. doi:10.1016/j.cub.2013.10.047

[120] Hepburn HR. The skeleto-muscular system of Mecoptera: the head. Univ Kansas Sci Bull. 1969;48:721-65.

[121] Bellmann H, Honomichl K. Biologie und Ökologie der Insekten. Jacobs W, Renner M, editors. Jena (Germany): Spektrum Akademischer Verlag; 2007.

[122] Rees BE, Ferris GF. The morphology of Tipula reesi Alexander (Diptera, Tipulidae). Microentomol. 1939;4:143-78.

[123] Imms SD. On the constitution of the maxillae and labium in Mecoptera and Diptera. Q J Microsc Sci. 1944;85:73-96.

[124] Gouin F. Recherches sur la morphologie de l'appareil buccal des Diptéres. Bull Soc Entomol France (NS). 1949;28:167-269.

[125] Blackwell A. A morphological investigation of Culicoides spp. biting midges (Diptera: Ceratopogonidae) from the Caribbean. J Vector Ecol. 2004;29:51-61.

[126] Crampton GC. The external morphology of Diptera. Bull Connect Geol Nat Hist Surv. 1942;64:10-165.

[127] Michelsen V. A revised interpretation of the mouthparts in adult fleas (Insecta, Siphonaptera). Zool Anz. 1996a;235: 217-23.

[128] Sutcliffe JF. Anatomy of membranous mouthpart cuticles and their roles in feeding in black flies (Diptera: Simuliidae). J Morphol. 1985;186(1):53-68. doi:10.1002/jmor.1051860106

[129] Gouin F. L'appareil buccal de Tipula sp. Stockholm (Sweden): VIIIth International Congress Entomol. 1950.

[130] Frey R. Studien über den Bau des Mundes der niederen Diptera Schizophora nebst Bemerkungen über die Systematik dieser Dipterengruppe. Helsinki (Finland): Dissertation University Helsinki; 1921.

[131] Gilbert F, Jervis M. Functional, evolutionary and ecological aspects of feeding-related mouthpart specializations in parasitoid flies. Biol J Linn Soc. 1998;63(4):495-535. doi:10.1111/ j.1095-8312.1998.tb00327.x

[132] Ngern-Klun R, Sukontason K, Methanitikorn R, Vogtsberger RC, Sukontason KL. Fine structure of Chrysomya nigripes (Diptera: Calliphoridae), a fly species of medical importance. Parasitol Res. 2007;100(5): 993-1002. doi:10.1007/s00436-0060426-2

[133] Elzinga RJ, Broce AB. Labellar modifications of muscomorpha flies (Diptera). Ann Entomol Soc Am. 1986;79:150-290.

[134] Schremmer F. Zur Morphologie und funktionellen Anatomie des Larvenkopfes von Chaoborus (Corethra auct.) obscuripes v.d. Wulp (Diptera, Chaoboridae). Österr Zool Z. 1950a;2-5: 471-516.
[135] v Lieven A. Functional morphology and phylogeny of the larval feeding apparatus in the Dasyheleinae and Forcipomyiinae (Diptera: Ceratopogonidae). Mitteilungen des Museums für Naturkunde Berlin. Dtsch Entomol Z. 1998;45:49-64.

[136] Beutel RG, Kristensen NP, Pohl H. Resolving insect phylogeny: the significance of cephalic structures of the Nannomecoptera in understanding endopterygote relationships. Arthropod Struct Dev. 2009;38(5):427-60. doi:10.1016/j.asd.2009.05.002

[137] Chaudonneret J. Le problème des messores des larves de Diptères Nématocères et la musculature labrale des insectes. Ann Sci Nat compr Zool. 1963;4:473-488.

[138] Stuke J-H. Phylogenetische Rekonstruktion der Verwandtschaftsbeziehungen innerhalb der Gattung Cheilosia Meigen, 1822 anhand der Larvenstadien (Diptera: Syrphidae). Stud Dipterol. 2000;(Supplement 8): 1-118.

[139] Sharif M. On the internal anatomy of the larva of the rat-flea, Nosopsyllus fasciatus (Bosc.). Philos Trans R Soc London, Ser B: Biol Sci. 1937;227(547):465-538. doi:10.1098/rstb.1937. 0007

[140] Whilm MW. The ecology, morphology, and phylogeography of the nearctic species Axymyia furcata (Diptera: Axymyiidae). Master of Science Thesis, Iowa State University; 2009.

[141] Bierbrodt E. Der Larvenkopf von Panorpa communis L. und seine Verwandlung mit besonderer Berücksichtigung des Gehirns und der Augen. Zool Jahrb (Abt Anat). 1942;68: 49-136.

[142] Melzer RR, Paulus HF. Evolutionswege zum Larvalauge der Insekten - Die Stemmata der höheren Dipteren und ihre Abwandlung zum Bolwig-Organ. J Zool Syst Evol Res. 1989;27 (3):200-45. doi:10.1111/j.1439-0469.1989.tb00345.x

[143] Sauer KP, Hensle R. Reproduktive Isolation, ökologische Sonderung und morphologische Differenz der Zwillingsarten Panorpa communis L. und P. vulgaris Imhoff und Labram (Insecta, Mecoptera). J Zoolog Syst Evol Res. 1977;15:169-207.

[144] Solinas M. Cephalic structures and special feeding habits in larvae of Cecidomyiidae (Insecta, Diptera): Biodiversity, evolution and ecology in action. Atti Accad Naz Ital Entomol. 2011;59:153-65.

[145] Courtney GW. Biosystematics of the Nymphomyiidae (Insecta: Diptera): life history, morphology, and phylogenetic relationships. Smithson Contr Zool. 1994b;550(550):1-41. doi:10.5479/si. 00810282.550

[146] de Jong H, Oosterbroek P, Gelhaus J, Reusch H, Young C. Global diversity of craneflies (Insecta, Diptera: Tipulidea or Tipulidae sensu lato) in freshwater. Hydrobiologia. 2008;595(1): 45767. doi:10.1007/s10750-007-9131-0

[147] Bauernfeind R. Die larvale Kopfmorphologie von Exechia separata (Mycetophilidae, Diptera) und ihre phylogenetische Bedeutung. Diploma thesis, Friedrich-Schiller-University Jena, 2014.

[148] Madwar S. Biology and morphology of the immature stages of Mycetophilidae (Diptera, Nematocera). Phil Trans R Soc B: Biol Sci. 1937;227(541):1-110. doi:10.1098/rstb.1937.0001

[149] Krogstad BO. Some aspects of the ecology of Axymyia furcata McAtee (Diptera, Sylvicolidae). Proc Minnesota Acad Sci. 1959;27:175-77.

[150] Craig DA, Chance MM. Filter feeding in larvae of Simuliidae (Diptera: Culicomorpha): aspects of functional morphology and hydrodynamics. Can J Zool. 1982;60(4):712-24. doi:10.1139/z82-100

[151] Lacoursière JO, Craig DA. Fluid transmission and filtration efficiency of the labral fans of black fly larvae (Diptera: Simuliidae): hydrodynamic, morphological, and behavioural aspects. Can J Zool. 1993;71:148-62. 
[152] Peus F. 17. Cylindrotomidae. Fliegen der paläarktischen Region 3 (5) 3. Lief. 1952;169:1-80.

[153] Podeniene V, Gelhaus JK. The first description of the larva of the crane fly genus Gonempeda Alexander 1924 (Limoniidae: Chioneinae), with new information for understanding the phylogenetic relationships of the genus. Proc Acad Nat Sci Philadelphia. 2002;152(1):67-73. doi:10.1635/0097-3157 (2002)152[0067:TFDOTL]2.0.CO;2

[154] Schremmer F. Morphologische und funktionelle Analyse der Mundteile und des Pharynx der Larve von Anopheles maculipennis Meig. Österr Zool Z. 1949;2:173-222.

[155] Gouin F. Recherches sur la morphologie de l'appareil buccal des Diptéres. Bull Soc Entomol France (NS) 1949;28: 167-269.

[156] Röber H. Morphologie des Kopfes und des Vorderdarmes der Larve und Imago von Sialis flavilatera. Zool Jahrb (Anat Ontogenie der Tiere). 1942;67:61-118.

[157] Sæther OA. Variation within immature stages of Chaoborus flavicans (MEIG.) (syn. Chaoborus alpinus Peus syn nov.). Int Rev ges Hydrobiol Hydrogr. 1967;52:573-87.

[158] Chiswell JR. On the last instar larva of Tipula livida van der Wulp (Diptera, Tipulidae) with notes on the fronto-clypeal region of larval Tipulinae and Caterpillars. Proc R Entomol Soc London. S A, Gen Entomol. 1955;30(10-12):127-36. doi:10.1111/j.1365-3032.1955.tb00168.x

[159] Hogue CL. Blephariceridae. In: McAlpine JF, Peterson BV, Shewell GE, Teskey HJ, Vockeroth JR, Wood DM, editors. Manual of Nearctic Diptera. Research Branch, Agriculture Canada, Canadian Government Publishing Centre, Hull, Quebec, Canada; 1981:191-198.

[160] Kevan DKMcE, Cutten FEA. Nymphomyiidae. In: McAlpine JF, Peterson BV, Shewell GE, Teskey HJ, Vockeroth JR, Wood DM, editors. Manual of Nearctic Diptera. Research Branch, Agriculture Canada, Canadian Government Publishing Centre, Hull, Quebec, Canada; 1981:203-208.

[161] Stone A, Peterson BV. Thaumaleidae. In: McAlpine JF, Peterson BV, Shewell GE, Teskey HJ, Vockeroth JR, Wood DM, editors) Manual of Nearctic Diptera. Research Branch, Agriculture Canada, Canadian Government Publishing Centre, Hull, Quebec, Canada; 1981:351-354.

[162] Foote BA. Tanyderidae (Tanyderoidea) - Chironomidae (Chironomoidea). In: Stehr FW, editor. Immature insects, Vol. II. Dubuque (Iowa): Kendall/Hunt Publishing Company; 1991: 730-762.

[163] Hinton HE. The phylogeny of the panorpoid orders. Annu Rev Entomol. 1958;3(1):181-206. doi:10.1146/annurev.en.03. 010158.001145

[164] Anthon H. Zum Kopfbau der primitivsten bisher bekannen Dipterenlarve: Olbiogaster sp. (Rhyphidae). Ein Beitrag zur Phylogenie der nematoceren Dipteren. Entomol Medd. 1943b;23:302-20.

[165] Keilin D. Recherches sur les larves de Diptères cyclorrhaphes. Bull Biol Fr Belg. 1916;49:15-198.

[166] de Meijere JHC. Zur Kenntnis des Kopfbaus der Dipteren Larven und Imagines. Zool Anz. 1916;46:241-51.

[167] Winkler D. Die Muskulatur der Larve von Limnophilus flavicornis Fabr. Dtsch Entomol Z (N.F.). 1959;6(1-3):112-28. doi:10.1002/mmnd.19590060112

[168] Fotius-Jaboulet M-C. Squelette et musculature ce' phaliques de la larve de Drusus trifidus Mac Lachlan (TrichopteraLimnophilidae). Trav Lab Zool Stn Aqui Grimaldi Fac Sci Dijon. 1961;40:1-54. (+Figs).

[169] Langhoffer A. Mandibulae Dolichopodidarium. Verh Int ZoolCongr, Berlin. 1901;5:840-46.

[170] Pohl H, Beutel RG. The evolution of Strepsiptera (Hexapoda). Zool. 2008;111(4):318-38. doi:10.1016/j.zool.2007.06.008
[171] Hannemann HJ. Die Kopfmuskulatur von Micropteryx calthella (L.) (Lep.). Morphologie und Funktion. Zool Jahrb (Abt Anat Ontogenie Tiere). 1956;75:177-206.

[172] Courtney GW. Revision of Nearctic mountain midges (Diptera: Deuterophlebiidae). J Nat His. 1990a;24(1):81-118. doi:10.1080/00222939000770071

[173] Schremmer F. Bau und Funktion der Larvenmundteile der Dipterengattung Dixa Meigen. Österr Zool Z. 1950b;2:379-423.

[174] Karandikar KR. The early stages and bionomics of Trichocera maculipennis (Meig.) (Diptera, Tipulidae). Trans Entomol Soc London. 1931;79(2):249-60. doi:10.1111/j.1365-2311.1931. tb00697.x

[175] Brindle A. A field key for the identification of Tipula larvae (Dipt: Tipulidae). Entomol Gazette. 1958;9:165-81.

[176] Wipfler B, Machida R, Müller B, Beutel RG. On the head morphology of Grylloblattodea (Insecta) and the systematic position of the order, with a new nomenclature for the head muscles of Dicondylia. Syst Entomol. 2011;36(2):241-66. doi:10.1111/j.1365-3113.2010.00556.x

[177] Beutel RG, Ge S-Q. The larval head of Raphidia (Raphidioptera, Insecta) and its phylogenetic significance. Zool. 2008;111(2): 89-113. doi:10.1016/j.zool.2007.03.005

[178] Wenk P. Die Muskulatur der Mandibel einiger blutsaugender Culiciden. Zoologischer Anzeiger. 1961;167:254-59.

[179] Das GM. The musculature of the mouth-parts of insect larvae. Q J Microsc Sci. 1937;80:39-80.

[180] Farnsworth M. The morphology and musculature of the larval head of Anopheles quadrimaculatus Say. Ann Entomol Soc Am. 1947;40:137-51.

[181] Beutel RG, Friedrich F. Comparative study of larval head structures of Megaloptera (Hexapoda). Eur J Entomol. 2008;105 (5):917-38. doi:10.14411/eje.2008.119

[182] Beutel RG, Hörnschemeyer T. Description of the larva of Rhipsideigma raffrayi (Coleoptera: Archostemata), with phylogenetic and functional implications. Eur J Entomol. 2002;99 (1):53-66. doi:10.14411/eje.2002.011

[183] Beutel RG, Molenda R. Comparative morphology of selected larvae of Staphylinoidea (Coleoptera, Poyphaga) with phylogenetic implications. Zool Anz. 1997;236:37-67.

[184] Szadziewski R, Krzywinski J, Gilka W. Diptera Ceratopogonidae, Biting Midges. In: Nilsson AN, editor. Aquatic insects of North Europe - a taxonomic handbook. Volume 2. Stenstrup (Denmark): Apollo Books; 1997.

[185] Otanes FQ. Head and mouth parts of Mecoptera. Ann Entomol Soc Am. 1922;25:310-23.

[186] Nixon KC. WinClada ver. 1.0000 Published by the author Ithaca (NY); 1999-2002.

[187] Neumann D. Adaptations of chironomids to intertidal environments. Ann Rev Entomol. 1976;21(1):387-414. doi:10.1146/ annurev.en.21.010176.002131

[188] Mamayev BM, Krivosheyna NP. New data on the taxonomy and biology of the family Axymyiidae (Diptera). Entomol Rev. 1966;45:93-99.

[189] Kennedy HD. Deuterophlebia invoensis, a new species of mountain midge from the alpine zone of the Sierra Nevada Range, California (Diptera: Deuterophlebiidae). Trans Am Microsc Soc. 1960;79(2):191-210. doi:10.2307/3224086

[190] Kennedy HD. Biology and life history of a new species of mountain midge, Deuterophlebia nielsoni, from eastern California (Diptera: Deutrophlebiidae). Trans Am Microsc Soc. 1958;77(2):201-28. doi:10.2307/3224115

[191] Hennig W. Die Larvenformen der Dipteren. 1.Teil. Berlin (Germany): Akademie-Verlag; 1968a.

[192] Hennig W. Grundzüge einer Theorie der Phylogenetischen Systematik. Berlin (Germany): Deutscher Zentralverlag; 1950. 
[193] Hasenfuss I, Kristensen NP. Skeleton and muscles: immatures. In: Kristensen NP, editor. Lepidoptera, Moths and Butterflies. Vol. 2: morphology, physiology, and development. Handbook of zoology. IV Insecta. Vol. 36. Berlin (Germany), New York (NY): Walter de Gruyter; 2003. p. 133-64.

[194] Förster M. Die larvale Kopfanatomie von Chaoborus christalinus (Diptera: chaoboridae). Bachelor thesis. FriedrichSchiller-Universität Jena; 2013.

[195] Dvash I. The larval head morphology of Axymyia furcate (Axymyiidae, Diptera). Master thesis, Friedrich-SchillerUniversität Jena; 2013.

[196] Beutel RG, Krogmann L, Vilhelmsen L. The larval head morphology of Xyela sp. (Xyelidae, Hymenoptera) and its phylogenetic implications. J Uoological Syst Evol Res. 2008b;46(2): 118-32. doi:10.1111/j.1439-0469.2007.00446.x

[197] Pohl H, Beutel RG, Kinzelbach R. Protoxenidae fam. nov. (Insecta, Strepsiptera) from Baltic amber - a 'missing link' in strepsipteran phylogeny. Zool Scripta. 2005;34(1):57-69. doi:10.1111/j.1463-6406.2005.00173.x

\section{COMPETING INTERESTS}

The authors declare no competing interests.

\section{PUBLISHING NOTES}

(C) 2014 K. Schneeberg and R.G. Beutel. This work has been published open access under Creative Commons Attribution License CC BY 4.0, which permits unrestricted use, distribution, and reproduction in any medium, provided the original work is properly cited. Conditions, terms of use and publishing policy can be found at www.scienceopen.com.

Please note that this article may not have been peer reviewed yet and is under continuous post-publication peer review. For the current reviewing status please click here or scan the QR code on the right.

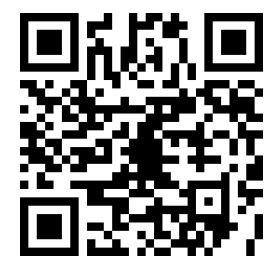

\section{ScienceOPEN.com

